\title{
The Role of Noradrenaline in Tuning and Dopamine in Switching Between Signals in the CNS
}

\author{
ROBERT D. OADES ${ }^{1}$ \\ Max-Planck-Institut für Hirnforschung, Deutschordenstr., 46, 6000 Frankfurt a M 7l, West Germany \\ and Laboratoire de Neurobiologie des Comportements, Université de Bordeaux II \\ 146 rue Leo Saignat, 33076 Bordeaux cedex, France
}

Received 17 June 1984

\begin{abstract}
OADES, R. D. The role of noradrenaline in tuning and dopamine in switching between signals in the CNS. NEUROSCI BIOBEHAV REV 9(2) 261-282, 1985.- Neuronal catecholaminergic activity modulates central nervous function. Specifically noradrenaline can exert a tuning or biassing function whereby the signal to noise ratio is altered. Dopamine activity may promote switching between inputs and outputs of information to specific brain regions. It has been ten years since evidence for a tuning function was advanced for noradrenaline [246,247] and in the last 5 years the switching hypothesis for dopamine has been tentatively put forward [39]. Recent studies are reviewed to show that while catecholamine activity contributes to neural interactions in separate brain regions that give rise to the organization of different functions, their working principles may be common between species and independent of the nucleus of origin. Behavioral examples are discussed and an attempt is made to integrate this with evidence from intracellular recording studies. It is suggested that the tuning principle in noradrenergic systems is particularly important for the formation of associations and neural plasticity (interference control) and that the switching principle of dopaminergic systems modulates the timing, time-sharing and initiation of responses (program-control).
\end{abstract}

Noradrenaline Dopamine Tuning Switching Learning Motivation Dorsal and ventral noradrenergic bundle Mesolimbic and nigrostriatal pathways Intracellular recording

Alpha and beta receptors D1 and D2 receptors Cyclic AMP

MOST studies of the functions of the catecholamines (CAs) in the central nervous system (CNS) have been related to the role of one transmitter or the other in one set of observed phenomena, often in a restricted part of the brain. The phenomena have been concerned with the physiological effects on the neuron and with the organization of a specific behavioral response.

In the last ten years evidence has slowly accumulated that indicates that there may be a specific working principle for the action of noradrenaline (NA) and another for dopamine (DA) throughout the CNS irrespective of the nucleus of origin. The idea is embodied in the term "modulation,"-an expression that was, by a curious coincidence, chosen independently by physiologists and by those studying organismic behavior [82]. Two types of modulatory principles will be discussed. The proposal is that NA activity tunes the relationship between the incoming signal and the noise from other sources (e.g., [171, 245-247]. DA activity facilitates switching between channels of activity in given brain regions (e.g., [39]).

This article is a select review. It is not my intention to discuss the truly vast literature on the involvement of the CAs in a large range of phenomena (see [165]), but rather to discuss recent data pertinent to the ideas embodied in these two working principles. The principles refer to the control of information flow. It is not surprising that many of the pertinent results discussed derive from studies of stimulus processing and learning. I have selectively referred to other behavioral systems in order to illustrate the potential generality of the hypothesis. This review avoids trying to provide an account for how behavioral systems (e.g., learning and motivation) or specific regions (e.g., frontal cortex and hippocampus) function. Hence the discussion for the most part concentrates on the "ascending" CA systems of the CNS.

I broach two questions-have these ideas come of age for the interpretation of phenomena observed by neurobiologists and are they compatible with our current knowledge of transmitter function at the cellular level?

\section{THE CATECHOLAMINE SYSTEMS-ANATOMICAL CONSIDERATIONS}

In man there are small groups of pigmented cells in the mid- and hind-brain known as the "blue place" (Locus coeruleus, LC) and the "black substance" (Substantia nigra, $\mathrm{SN}$ ) that synthesize the neurotransmitters NA and DA re-

\footnotetext{
${ }^{1}$ Requests for reprints should be addressed to R. D. Oades, Department of Human Physiology, Flinders Medical Centre, Bedford Park, South Australia 5042.
} 
spectively. Throughout the vertebrates there are small groups of NA- and DA-cells in the brain stem, although the pigment is usually lacking.

In mammals NA fibers originate in the A6 (LC) and A7 nuclei in the dorsal lateral pontine tegmentum and more caudally in the dorsal (A2, A4) and ventral (A1, A5) brain stem (lateral tegmental field; see [113] for details). DA fibers arise from the A8-A 10 nuclei located ventrally in the midbrain (SN/A9 and ventral tegmental area, VTA/A 10). There are also incerto-hypothalamic and tubero-infundibular (A11-A 14) DA systems [3, 47, 138, 185]. Amongst the mammals, the number of cells in these nuclei increases with animal size and evolutionary progression (SN:VTA cell ratios; mouse-1: rat-2.5: cat-5.5: primate-17) $[78,217]$. Even if only a proportion of these cells actually contain DA (in SN 1/3+; VTA-2/3 [5, 98, 265]) this number is markedly higher than the number of cells in the NA system (circa 20:1; e.g., LC, rat-1500; man-20,000) $[35,288]$.

NA fibers ascend in the medullary bundle (more rostrally the central tegmental tract), the dorsal tegmental and periventricular systems [137]. These fiber systems are often referred to in functional studies as the dorsal and ventral NA bundles to reflect the origins (A6 vs. A1, 2, 5, 7) and the areas they innervate (neo/allo-cortical vs. subcortical areas) respectively. At the level of the hypothalamus most ascending NA fibers are found in the medial forebrain bundle (MFB). DA fibers arising from the A\&-10 nuclei are also found in the MFB. One can make two broad generalizations on the projection pattern of these DA fibers. First, the more laterally placed cells project to more lateral regions of the forebrain; second, whereas the A9 group projects more toward the basal ganglia, the A10 group projects more to areas that are cortical or limbic in structure or function [138, $185,248,255,265]$.

With the increasing size of the forebrain during vertebrate evolution the CA-fibers increased their distribution and gained the ability to modulate the functions of newly developing regions without losing their influence on the more primitive structures. Both NA- and DA-terminals develop in the neo-, archi- and paleo-cortices, the hypothalamus and thalamus, the cerebellum and brainstem.

However, the pattern of innervation, at the macroscopic level, and the terminal field arrangement, at the microscopic level, differs for the two CA systems. In contrast to what one might expect from the relative number of cells in the DA and NA nuclei, NA neurons show a far more extensive pattern of collateralization. No cortical cell is further than $30 \mu \mathrm{M}$ from an NA-containing bouton [54]. Thus, in the rat, for example, the LC system projects to all parts of the frontal cortex whereas the VTA system projects to specific layers of the anteromedial, supragenual and suprarhinal prefrontal cortex [139]. The neocortex shows a diffuse NA innervation, but a specific and localized DA innervation [187]. Whereas NA neurons often show a broad network of numerous collaterals in their terminal fields, DA neurons ramify more abruptly at their ends into dense "nest- or basket-like" aggregations around other cells $[139,184]$. But within the VTA there are more laterally and more medially situated cell-groups with different pharmacological characteristics [252] and anatomical features, whereby the lateral group shows more collateral connections than the medial group [143]. Last, but not least, it is important to note in a review of the modulatory roles of the CAs that there is a greater propensity for many more NA than DA terminals not to be associated with classical postsynaptic contacts [15].

\section{CATECHOLAMINE FUNCTION: THE LEVEL OF ANALYSIS}

I have sketched the anatomical bases in such a way as to facilitate thinking of $\mathrm{CA}$ projections as systems-systems that are unlikely to mediate a phrenological mosaic of separate and specific functions. However the sheer breadth of the $\mathrm{CA}$ involvement in brain function does not encourage positing common principles of CA action and function. NA- and DA-pathways play a role in the control of eating and drinking; of reproductive, stress-related and motor behavior; of attention, memory and intracranial self-stimulation (ICSS) (reviews $[3,7,37,162-165,189,230]$ ).

Without wishing to question the breadth of the work that led to these conclusions, such a spectrum encourages thinking of a role for CA systems, perhaps, in terms of "volume control" rather than mediating the "melody" [55]. Use of this analogy easily leads (by turning the control knob) to the concept of "enabling" or "disenabling" the actions of other transmitter systems $[23,82]$. One further step in the development of this analogy leads to the possibility of tuning (signal to noise and/or volume), the proposed role for NA systems, and of switching (on/off, between information sources), the proposed role for DA systems.

Thus the proposed explanations of the roles of NA and DA in mediating the functions listed above are pitched at the level of signal propagation or what happens when CAs are released in a population of neurons to which and from which a large number of fibers project. The evidence comes from two extremes-from the analysis of events in a single neuron and changes of behavioral responsiveness of the organism as a whole.

\section{NORADRENALINE, THE RELATION OF SIGNAL TO NOISE}

The principle for NA function states that an increase of $\mathrm{NA}$ activity promotes the processing of the signal arriving in an assembly of components in the region of the NA projection rather than the noise arising from other activity. In other words, NA activity promotes the processing of important information rather than that which is less relevant to the ongoing state of the system (or animal). The result is that NA activity can facilitate the processing of some information (e.g., signals) but impede that for other information. But, as we shall see below, it is important to note that the inverse is not necessarily true. That is to say the absence of NA activity does not automatically prevent the processing of signals (Fig. 1).

Such a role, whereby the amplitude of a signal may be biased in comparison to other input, has the advantage of resolving the paradox that interference with NA-systems may under one set of conditions potentiate a range of behavior, but under other circumstances may depress the same behavior [7]. I shall discuss how these opposite effects could be mediated at the level of a single neuron after describing examples of tuning the signal to noise ratio at the level of behavioral responsiveness, the activity in a neuronal system and some of the technical difficulties that make the interpretation of these results difficult (next 3 sections).

\section{Some Methodological Problems}

Two areas of investigation have provided good evidence for the "tuning" principle by an exemplary combination of neurophysiological and behavioral techniques (next section). But if this is a principle for NA function it should apply to the processing of signals whether they relate to stimuli from 

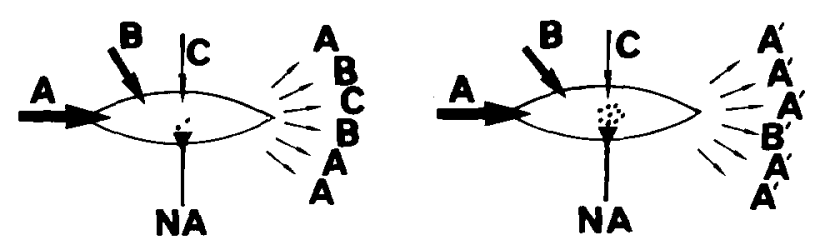

\section{LOW NA ACTIVITY HIGH NA ACTIVITY}

\section{processing related to input salience.}

\section{biased processing of significant input ' $A$ '.}

FIG. 1. A schematic representation of a brain region receiving noradrenergic (NA) input and three varieties of information (sources $A, B$ and $C$ ). The size of the arrows represents three degrees of information salience. Where there is little NA activity (left) the region relays information in proportion to its incoming salience: where there is increased NA activity (right) the output is transformed, here, biassed to $A$. The assumption is that the nature of the inputs has not changed but the decision has been made that $A$ now represents significant information (i.e., stimulus with consequences).

without (e.g., attention and learning) or from within (e.g., stress and the consolidation of stimulus traces). (The putatively different requirements of retrieval will be discussed later.) In the main the relevant studies are behavioral and pharmacological. Their results are somewhat contradictory and controversial. Let us briefly consider some of the technical reasons, often overlooked, that may help to explain this.

(I) Electrical brain stimulation. Such studies aim to mimic or to enhance the function of the area under study. But, clearly, as Salafia and Allan [238] showed, too high a current density or an inappropriate pulse frequency can lead to lesion-like effects. Further the LC does not only consist of NA somata. Other components can be activated by different stimulus parameters. Thus, for example, LC stimulation with $0.05 \mathrm{msec}$ square pulses of $2-5 \mathrm{~V}$ repeated for several seconds at $200 \mathrm{~Hz}$ can lead to an excitation of lateral geniculate relay cells. This can be prevented by alpha methyl para tyrosine or alpha-NA blocking agents. However a very brief pulse train $(5$ pulses at $500 \mathrm{~Hz})$ can apparently lead to an NA-independent suppression of the relay neurons [120].

(2) Brain lesions. The goal of such damage is usually to deplete NA levels and reduce NA activity in the forebrain. It is often (conveniently) overlooked that electrolytic lesions affect the function of non-NA components but such lesions are often less effective on NA systems than chemical lesions ([37] Table 1). Further lesions may be made in the ascending fiber bundle or in the LC itself. The result of damage to the sum of the ascending fibers and the impairment to the sum of the functions of the brain regions affected may not be the same after the destruction of the DNAB and the LC [95]. For example, electrical stimulation of the $\mathrm{LC}$ is claimed to facilitate subsequent task acquisition. The reported effect is significantly attenuated by LC lesion (with 6-hydroxydopamine, 6-OHDA) but is left relatively intact by DNAB damage (with 6-OHDA) [286]. Another example is the increase of copulatory behavior in rats seen after electrolytic LC lesions but not after damage with 6-OHDA [37]. $A$ non-DNAB pathway projects from the LC to the hypothalamus $[137,169]$.
(3) NA levels. (a) Decreases are often treated as synonymous with decreased activity, although it is accepted that the same result for DA can reflect increased levels of metabolites and transmitter utilization. (b) With an appropriate survival time the toxins 6-OHDA and DSP4 are used to deplete NA levels. These treatments can lead to supersensitivity, but this is likely only if depletion is clearly in excess of $90 \%[62,280]$. Depletions above and below this level can lead to opposite results. Even then, some studies report no increase in receptor number after $93 \%$ NA depletion with 6-OHDA [53] or 42-94\% NA depletion with DSP4 [62]. (c) 6-OHDA lesions of the DNAB can reduce DA levels in the caudate nucleus and NA levels in the hypothalamus by 25 $50 \%$, respectively (cf. Table 1). But explanations of behavioral changes caused by such treatment are seldom sought in these brain regions or in the interactions between DA and NA (cf. $[95,268]$. (d) Small and large changes may be significant for the interpretation of results. Thus mild stressors and novel stimuli can increase the release of NA by $20 \%$. This is a small change that markedly reduces the dose of adrenergic agents necessary to affect retention performance [82]. At the other end of the scale, an increase from $10 \%$ to $23 \%$ of cortical NA (after 6-OHDA lesion) markedly reduces the performance deficit seen during the extinction of partially reinforced responding [209]. Yet, studies routinely include animals with $50 \%$ cortical NA in their experimental groups showing a "major" NA deficit.

(4) Behavioral tests. Their design for the study of NA function, as with the study of brain function in other fields of research, often invite rather than allay controversy. Despite claims to the contrary, reports seldom replicate each other (e.g., maze alternation $[166,175,215])$ and make improbable assumptions (e.g., on the nature of a stimulus that should distract $[9,58])$.

It is not the purpose of this article to review the technical features of all studies of NA function, but with the caveats listed briefly above it is possible to draw together the threads of direct and correlative evidence for the proposed NA working principle.

\section{The Principle in NA Systems: Primary Evidence}

The first example comes from the study of visual perception [140]. Under conditions of arousal (waking) the excitatory and inhibitory components of the response of cells recorded in the lateral geniculate nucleus of cats to spatially restricted visual stimuli were enhanced. Responses from both the receptive field center and the antagonistic surround were enhanced. Visually evoked responses in the striate cortex were easier to observe against a more regular or reduced background firing when the animal awoke (i.e., signal amplification and spontaneous background reduction). There have been numerous reports of the correlation between neuronal activity in the LC, the EEG and behavioral measures of arousal $[140,177]$. Indeed electrical stimulation of the LC further exaggerated the changes of visual response that were seen on waking $([140,149]$ cortical iontophoresis of NA [119]). Facilitation of reactivity, through application of NA or LC stimulation, is improved when stimuli are presented with the optimal orientation or direction for the specific cell recorded. No facilitation is observed if the least optimal mode of stimulus presentation is employed [244]. Similar results have been obtained from the somatosensory [292, 298, 299] auditory cortices [71] and the cerebellum [73].

A second important example comes from the study of 
hippocampal function in rats [245-247]. The firing of the pyramidal cells tends to be inhibited after the animals have heard a loud tone. Electrical stimulation of the LC inhibited the spontaneous firing of most hippocampal cells. These responses were antagonized by agents that interfere with NA transmission. The responses of cells to non-significant tones were augmented (usually further decreased) by preconditioning stimulation of the LC. However if the tone signaled milk reinforcement, an excitatory response was recorded that was significantly increased by stimulation of the LC. In particular, priming stimulation of the LC facilitated the formation of late components in the reactivity of the hippocampus to afferent stimulation [244]. Here is a mechanism whereby excitation to non-significant stimuli is reduced, but the "signal to noise" ratio for a response to significant stimuli is increased. In this way, the dorsal NA system may perform a useful filter-like role in selective attention by reducing the chance of response to irrelevant stimuli (noise) (cf. further discussion in $[163,164,171,173])$.

\section{Secondary Evidence: A Background of NA Function in Information Processing and Behavior}

How far does our current understanding of NA systems fit the idea of tuning? Here I attempt to make a resumé of findings, some controversial, with particular reference to the role of NA in the processing of stimuli and signals. In advance I should point out a feature implicit in the tuning hypothesis. The absence of NA activity may hinder the processing/tuning of a signal and the subsequent development of appropriate behavioral change but, in contrast to the absence of DA activity, one would rarely expect processing to be blocked. Rather the performance may simply not attain the level shown by controls since the "signal" does not stand out from the noise. Alternatively the "signal" may take longer to come to control behavior.

Single and multiple unit activity in the LC increases with the state of wakefulness [11]. Units are sensitive to polymodal inputs [12] and respond in particular to novel [290] and interruptive stimuli [11]. Novel stimuli, exploration and mild stressors elicit a small (c. 20\%) and transient (10 $\mathrm{min}$ ) release of $\mathrm{NA}$ in the terminal regions $[82,264]$.

The mobilization of NA may assist an animal to notice and to learn about the significance (or lack thereof) of new stimuli. The implantation of NA into such regions may enhance responses to novelty, such as rearing (e.g., hippocampus $[70,216]$ ), or may suppress it (e.g., basal ganglia [264]), depending on the region and the nature of the interaction of NA with other transmitter systems. However, as the amount of NA released in novel situations is small, it is not surprising that 6-OHDA lesions have usually been reported to result in little (DNAB [287,294]; VNAB [287]) or no change of exploratory behavior, whether placed in the adult or the young rat $[107,210,236]$. But pre-/peri-natal treatment with 6-OHDOPA, that crosses the placental barrier, did cause an increase of hole-exploration and locomotion $[126,186]$. The plasticity of the system is indicated by the attenuation of this effect between 5 and 8 weeks of age. This could account for the negative result from Crow and his colleagues [45] or the marginal increase found in the holeboard by the same authors [294] — so long as there were objects under the holes.

Of clear importance is whether the novel stimuli elicit or concur with corticosteroid (CS) changes. Thus the one study found lesion induced locomotion increased with increasing
CS levels [126] and the other found less attenuation of exploration over time in adrenalectomized animals [294]. This may account for the slight attenuation of habituation reported by Mason and Fibiger [166] as measured by the number of contacts (if not the latency) to a novel object. Relatively few studies record CS levels unless actively investigating stress mechanisms. It is interesting that in the case of "double novelty" (novel food/object in a novel environment) a reduction of NA levels (6-OHDA [161]; DSP [4,52]) led to the other extreme of enhanced neophobia (originally observed [176]). Animals appeared to be unable to attenuate their reactions to "double novel" stimuli like controls even though neither emotional behavior [52] nor CS levels [161] seemed to be altered. (Apparently DSP4 treated and control rats, drinking a novel solution from creaking bottles, did not show differential levels of neophobia [9]. However, one reading of their continuing taste aversion experiment would suggest that an interference of NA depletion on the subsequent consolidation of the task may have derived from the initial unmodulated "double novelty" exposure.)

Conclusive evidence that NA activity contributes to the elaboration of the startle response to a loud noise is lacking. Lesions of the DNAB or VNAB are reported to show little [51,79] or no effect [287]. However, levels of NA remaining in the CNS and particularly NA activity in the unaffected descending spinal afferents may be sufficient to mediate normal startle responsiveness. Treatment with either the alpha agonist clonidine [51], which depresses levels of NA metabolites $[121,296]$, or a dopamine decarboxylase inhibitor (diethyl thiocarbamate [262]) depress the amplitude of the startle response quite strongly. But it is not clear from these reports whether this may be attributable to a general decrease of locomotor activity and sedatory effect of these drugs. (see addendum)

Does NA activity assist in the processing of stimuli pertinent to task solution? The rate of disappearance of central ${ }^{3} \mathrm{H}-\mathrm{NA}$ has been correlated with the acquisition of a two-way active avoidance (Hraschek et al. [131]). The utilization of cortical NA in this paradigm increased by $41 \%$ [59]. This is the same order of magnitude as is induced by inescapable shock. However, Kovacs and his colleagues [131] showed that normal rats that performed a one-trial step-through passive avoidance well, had double the NA turnover in the dentate gyrus of the hippocampus of those which learned poorly. (The role of the hippocampus in the selective aspects of learning [271] and the dentate gyrus in the corruption of information [215] has been well documented.) Further a series of studies in Bordeaux has shown that electrical stimulation of the MFB or of the LC (not SN, N. accumbens or parietal cortex) can facilitate both the acquisition and reversal of light/dark discriminations. This effect has been reported for both appetitively and aversively reinforced tasks [248, 285, 286].

Early reports of lesion-induced acquisition deficits (e.g., $[6,44,167])$ either could not be replicated $[234,294]$ or have been reinterpreted $[173,230]$. Generally speaking, the DNAB lesion does not grossly impair the acquisition of simple discriminations between spatial cues $[30,92,214,263]$ or standard passive/active avoidance tasks $[230,250]$. When the demands of the task are simple (the message comes through without tuning) or NA activity is not eliminated (cf. Table 1) this statement should not come as a surprise (see first paragraph in this section). However, more recently, several laboratories have looked again at task performance after depletion of NA. 
TABLE 1

SELECTED REPORTS OF NORADRENALINE (NA) AND DOPAMINE (DA) LEVELS (\%) AFTER VARIOUS “NORADRENERGIC" LESIONS

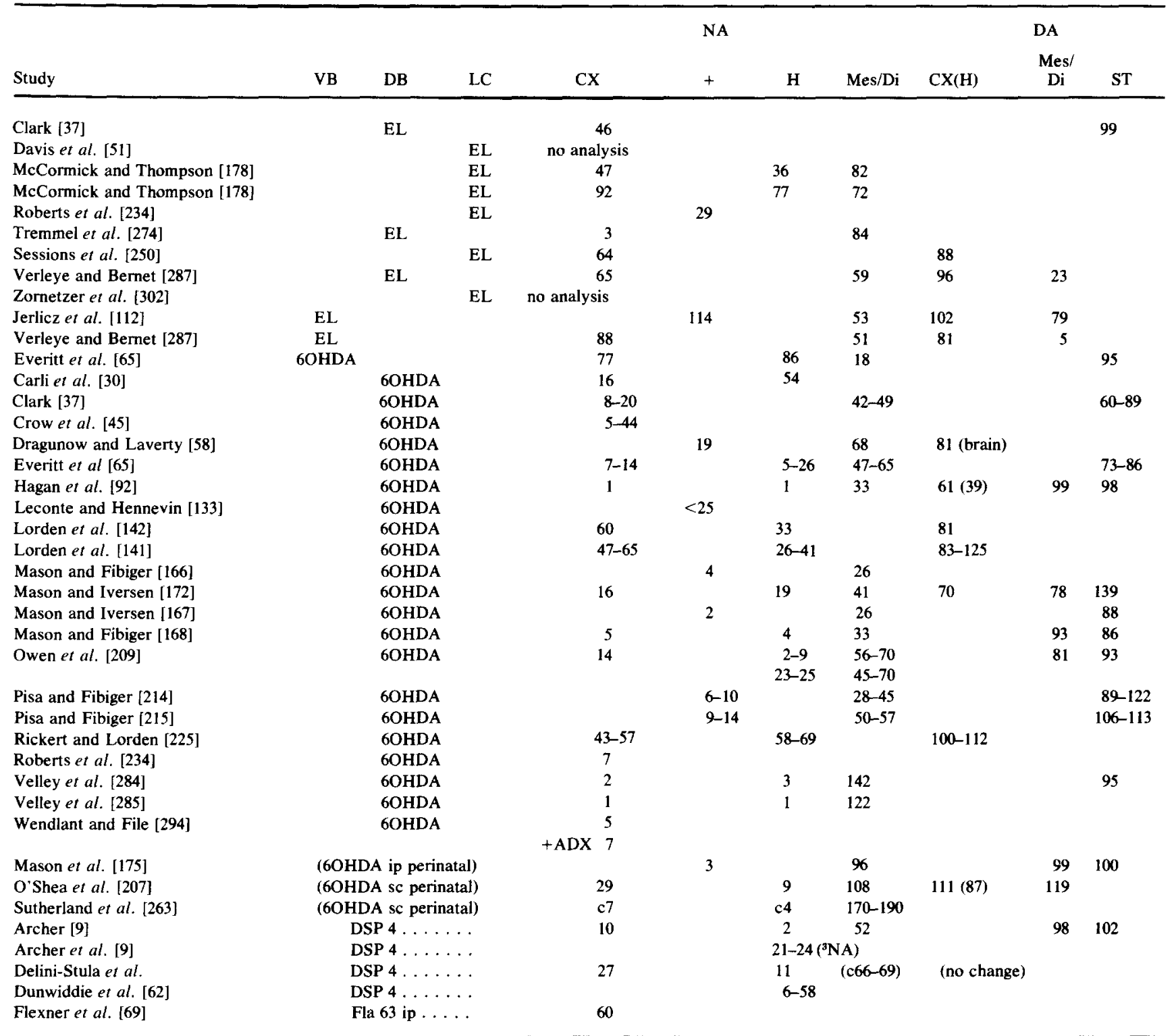

E-L, electrolytic; 6-OHDA, 6-hydroxydopamine; DSP 4, N2-chloroethyl-N-ethyl-2-bromobenzylamine; VB, ventral bundle; DB, dorsal bundle; LC, locus coeruleus; CX, cortex; H, hippocampus; Mes/Di, mes-/di-encephalon; ST, neostriatum.

If numerous choices are introduced to a maze, lesioned animals may not reach as high a learning criterion as controls [133]. The same problem was shown on temporal discriminations-it was easier for the DNAB group to reach a learning criterion of $67 \%$ than $85 \%$ [232]. A similar problem with the achievement of a strict learning criterion has been observed after DSP4-induced NA-depletion on discriminated or active avoidance tasks [9] or by the addition of adrenalectomy to the 6-OHDA lesion $[205,206]$. In a similar vein, more complete destruction of the DNAB system can be achieved with 6-OHDA if animals are treated perinatally. Such manipulations may suppress the beneficial effects of enriched rearing on learning a Lashley III maze [207], may abolish the sparing observed after frontal damage in finding a platform submerged in an opaque fluid [263], and may even slow down the rate of acquisition of a spatial alternation task [175]. Indeed, with the emphasis on the complexity rather than the lesion technique, if a complex temporal discrimination (in the auditory or visual modality) is presented to rats with 6-OHDA-DNAB lesions an acquisition impairment may be recorded [65].

It seems that the signal must be embedded in other information and/or the levels of NA must be well depleted in order for a lesion-induced impairment to be seen. But, what about the performance of lesioned animals in the presence of clearly irrelevant stimuli (e.g., in the paradigms of distraction and learned inattention)?

It is no surprise to learn that a loud noise interrupts (or 
not) ongoing behavior as much in normal as in lesioned animals $[30,45,58]$. But if the stimulus load is increased more subtly (e.g., decrease of interstimulus interval) the DNAB-lesioned animals show an impairment of accuracy of their learned performance [30,229].

If an animal is preparing a decision, NA depletion should lead to a relative inability to tune out potentially relevant stimuli. This has been demonstrated by presenting visual/auditory stimuli that were related to but irrelevant to a visual/auditory discrimination to rats that were partially trained [65]. Similarly, a transient, increased distractibilty has also been reported when the overhead lighting was changed before an operant response [168] a white noise was played before the visual discriminanda were presented [30] or when rats were required to walk past unexpected visual and tactile stimuli on the way to a runway goal box [234].

If a decision to respond has been made, then an impairment of the tuning mechanism would reduce the likelihood of a new stimulus interrupting or controlling behavior. Thus a transient decrease of distractibility was found when a tone was played while water-deprived animals were drinking [58], when the bottles made noises during drinking [9] or when eye-level lighting changed during operant responding [168]. (The absence of a distracting effect when stimulus brightness decreased [30] may be ascribed to the perseverative intertrial responding shown by animals that had clearly welllearned the discrimination.)

In this context, another sort of "distracting surprise" is the omission of expected reinforcement (extinction). In accordance with the preceding paragraph, the delay in tuning out the learned, now irrelevant stimulus, from controlling behavior is well documented for a range of operant $[10,58$, $209,214,215,273,274]$ and classical conditioning tasks [ 170 , 172, 178]. Owen et al. [209] have also pointed out that the reduction of partial reinforcement effects on acquisition of a runway task (run speed increased) and its extinction (resistance diminished) support the hypothesis of NA modulating the control of behavior, in this case, by "significant signals" of non-reward.

In the latent inhibition task (LI) pre-exposure to nonreinforced stimulus(i) retard(s) subsequent conditioning to the stimulus(i). An attenuation of LI should be found after inadequate learning of the "insignificance" of the stimulus in the pre-exposure phase or enhanced flexibility (switching or tuning) when reinforcement then (surprisingly) follows. The first phase is notoriously sensitive to the mode and number of stimulus presentations, handling and the degree of familiarization with the apparatus: these variables alone could account for various contradictory results $([21,293]$, Oades unpublished results). An acquisition impairment in this first phase, as has been reported by Everitt et al. [65], has been advanced to explain the LI attenuation claimed for DNAB rats [174]. Such a "floor-effect," whereby both exposed and non-exposed animals showed some acquisition deficit in the reinforcement phase, may have prevented a further LI deficit from becoming apparent [65]. Indeed Archer and his colleagues have reported a contextdependent enhancement of LI in DSP4-treated rats in a conditioned taste avoidance task [9].

In the absence of severe learning impairments following NA depletion it is not surprising that LI has been observed similarly in controls and NA-depleted animals in simple operant (6-OHDA [141]) discrimination (6-OHDA [232]) and active avoidance learning (DSP4 [8]). In view of the tuning function ascribed to NA, it might be more pertinent to ask what happens when NA activity is stimulated in such situations. I am not aware of such an experiment having been reported.

However, remembering the effect that "double novelty" had on NA-depleted rats, it is of interest that Lorden and her colleagues [141] found an attenuation of LI in 6-OHDA treated animals after a few exposures (contrast [232]) to $t w o$ stimuli. Even mild decreases of NA in 6-OHDA-DNAB treated rats can induce an equivalent responsiveness towards both novel and pre-exposed stimuli [225]. The same group had earlier reported an attenuation of the conditioned blocking of a conditioned emotional response, where the second stimulus (e.g., light) is redundant to the first signal (e.g., tone) of impending foot-shock [142]. I suspect that this group obtained these effects because they used situations where animals inevitably had to assess the relative significance of two stimuli (an essential role for NA). However, I believe the results may not reveal very much about the nature of the putative NA-modulated attentional mechanisms [148], but rather can be interpreted in terms of distraction in the pre-decision phase of learning (see above).

Other types of task require an animal to be flexible and to change-a new relevant modality supersedes the previous one (transfer) and/or the operant (level) may be changed (reversal). DNAB lesions impair the "new acquisition" [232]. In both cases, only a poor learning criterion is easily achieved. But this line of experimentation, where previous learning plays a role, throws another point into relief-namely the consolidation and/or retrieval of the trace of a significant stimulus. The transfer of such a trace from a state vulnerable to interference to more secure storage (and vice versa for modification) also requires selective processing. What may prove to be a good example here is the $1 / 3-2 / 3$ increase of forebrain NA (not DA) found associated with the visual experience of imprinting in chicks [49].

LC lesions (E-L) immediately after acquisition of a 1-trial passive avoidance prolong the period of susceptibility of this learning to disruption by electroconvulsive shock from a few hours to at least a week [218,302]. Learning of a shockmotivated Y-maze discrimination by mice remains susceptible to localized (temporal) disruption by puromycin for 1-3 months if the animals are repeatedly treated with dopamine- $\beta$-hydroxylase inhibitors [69]. By contrast, posttrial treatment with NA is one of several that can enhance the retention of shock-avoidance training in rats and mice $[81,220]$. This effect seems the more specific considering that NA synthesis inhibition itself can result in amnesia $[93,220$, 222]. This amnesia can be reversed by phosphodiesterase inhibitors that raise levels of cAMP. (N.B. $\beta$-receptor is linked to adenylate cyclase: LC lesions increase $\beta$-receptor density [251].)

Not only consolidation but retrieval processes are implicated. Rats tend to "forget" what they have learned about a 6-choice maze after a pause of 25 days. Exposure to contextual cues improves their performance. It is precisely such an exposure that increases NA utilization (MHPG increase) in the hippocampus (but not the cortex) $[239,240]$. The correlation between a suppression of CSF NA metabolites and the degree of memory deficit in Korsakoff patients [179] could support this result, but this has not been confirmed [160]. Nonetheless, marked regional depletions of NA with degeneration-compensating increases of utilization do correlate with increased dementia [84].

At the level of interpretation of function in this article there need be no a priori distinction between an electrochem- 
ical signal representing newly perceived stimuli or those representing a mnesic trace. Both may control or be affected by motivational changes and the organismal state (e.g., anxiety). In each case there will be a series of events and a role for tuning the one with respect to the other. Indeed, Gray [89] has included a similar "attention-related" role into his theory on anxiety. (Increases of NA activity, anxiety and arousal (and the relation of the possible overtuning of events) are reviewed in $[34,88]$.) The argument should not get bogged down in specific cognitive constructs nor in specific attributes of brain region or systems. For example, the amygdala may process positively reinforced associations and the hippocampus the negatively reinforced ones $[94,104]$. With NA actively involved in both functions and in both regions $[10,131]$, it is little wonder that damage to both structures impairs information processing more than to either alone [183].

With respect to the tuning hypothesis, the same type of generalization can be applied to dorsal and ventral NA systems, even if their different projection regions are involved in processing different types of information [197]. Ventral NA systems may intervene directly in the processing of stimuli associated with positive reinforcement via the motivational and neuroendocrine systems of the hypothalamus and neighbouring brain regions $[230,283]$. However, in view of the widespread interconnections of the ventral NA system with subcortical DA systems [204], it seems likely that NA would modulate other monoaminergic signals as they reach the basal ganglia and projection regions of the VNAB $[128,130]$. This may also help to explain the findings that many parts of the dorsal and ventral systems as well as projection regions of the DA system will support intracranial self-stimulation $[77,228,246,260]$. It would also provide a reasonable interpretation for reports of increased explorative locomotion in the open field and facilitated acquisition of conditioned avoidance after ventral bundle lesions [112,129]. Thus there is no reason to suppose that the ventral NA pathway has a fundamentally different role from the dorsal route where the level of argumentation is pitched at modulation by tuning (cf. also [287]).

In conclusion, I have largely concentrated in this section on studies relating to the NA involvement in learning rather than motivation and anxiety. The arguments should pertain to the latter, but since they are expressed in terms of information processing, it is easier to review the fit of the hypothesis to results from studies of learning. These studies offer some correlative support to the tuning hypothesis. Where there are apparently paradoxical results, they are likely to be explicable in terms of the type or degree of NA depletion and post-lesion recovery of function (cf. increasing depletion, E-L vs. 6-OHDA, 6-OHDA-DNAB vs. 6-OHDA-LC and DSP4-ip or the experimental protocol (e.g., distinction of stimulus presentation in conditioned inhibition paradigms from those for distraction and reversal).

NA activity assists in tuning all classes of internal and external stimuli in the CNS. But its role is not absolutely essential. This means that decisions over processing one rather than another set of stimuli can be made independently of NA activity. Thus NA activity has less marked effects on well-learned behavior, but noticeable effects if decisions have not been clearly made and consolidated. Future elucidation of the specific action of NA should beware of neurobiological or cognitive reductionism and embrace a wider spectrum of neurobiological and behavioral manipulation. With the current emphasis on lesion studies, it may be relevant to transliterate the dictum from behavioral pharmacology-that a given manipulation may impair the performance of a subject does not necessarily imply that the opposite action specifies normal function.

\section{On a Neuronal Mechanism}

In this section neurophysiological studies will be discussed to show how apparently opposing effects, with regard to the behavioral responsiveness to given stimuli, might be mediated at the neuronal level (cf. original sources-section on primary evidence).

The first stage was the demonstration that NA, an "inhibitory" transmitter, can facilitate the action of excitatory transmitters by a presynaptic action. We can illustrate these effects from recent work from the laboratory of Nicoll $[111,150]$. Electrical pulse stimulation of mitral cells in the olfactory bulb of turtles elicits field potentials in the granular cell layer that result in a GABA-mediated feedback inhibition of a response to a second excitatory stimulus. Iontophoresis of NA onto the granular but not to the mitral cells attenuated this feedback. Thus NA can play a disinhibitory role. An inhibitory transmitter can both facilitate (mitral) and attenuate (granular) neural activity. Similar mechanisms have been proposed for other inhibitory substances such as the opioid peptides [190].

More interesting still is the demonstration of opposite effects in the same neuronal population [150]. CA1 pyramidal cells in the rat hippocampal slice will produce a burst of spikes in response to a depolarizing current. The iontophoresis of NA can hyperpolarize the membrane and hence depress the response to threshold current. However, an activation (increase of the number of spikes in a burst) can be achieved by the application of excitatory amino acids or increasing the pulse current. The effect is agumented by NA. It is achieved by blocking the slow $\mathrm{Ca}^{2+}$ activated $\mathrm{K}^{+}$conductance changes that follow depolarization (cf. also [243]). The effect is dependent not on the alpha receptor but the adenylate cyclase-linked beta receptor. Thus NA can both suppress weak inputs and enhance strong inputs at the same time.

Here the possibility is raised that one may be able to infer which of these processes dominates in a particular area by noting the differential distribution of alpha- and betareceptors [188]. One may note that the facilitation of learning that followed LC stimulation (see above) correlated with a larger increase of alpha than beta receptors in the cerebral cortex [284]. Perhaps paralleling this, Kayama et al. [120] noted that it was alpha and not beta blockers that inhibited the spontaneous discharge and threshold changes of the lateral geniculate which followed LC stimulation.

In contrast, with respect to the animals that we noted to perform well on a passive avoidance task, it is interesting to note that a large proportion of the NA receptor sites in the dentate gyrus (where the increased NA activity was noted) belong to the beta class [46]. Kasamatsu et al. [119] found that the recovery of binocular vision after monocular deprivation could be disturbed by local application of beta blockers in the visual cortex.

Speculatively, alpha receptor stimulation may be arousing and may increase the potential for excitation by a broadening of bandwidth. Whereas beta stimulation tunes out the disturbance, improving the signal to noise ratio [23]-the signal may be potentiated or extended in time [229] by a focussing of bandwidth. 
Haas and Konnerth [91] have recently provided electrophysiological confirmation of the involvement of beta receptors. After perfusing the hippocampal slice with NA they found that the beta receptors of the CA1 pyramidal cells mediated a rapid and reversible decrease of the late afterhyperpolarization component that follows a burst of spikes. Such a result could then lead to a potentiation of the "excitatory impact of depolarizing signals" [91]. This effect, achieved at a concentration of $10^{-5} \mathrm{M}$, is astonishingly similar to that of DA at $10^{-6} \mathrm{M}$ (see DA section). But there is reason to believe that the detailed causal circumstances (e.g., involvement of the $\mathrm{Ca}^{2+}$ spike and adenylate cyclase) may also differ between the NA- and DA-elicited changes.

However, before these results can be generalized or confidently interpreted, it is necessary (1) to compare and contrast the results from neurons in other brain regions (cf. in the lateral geniculate where the alpha ${ }_{1}$ receptor seems to play an important role in mediating the excitatory response to LC stimulation [235]), and (2) to find out more about the rules underlying the adenylate cyclase mediated effects on $\mathrm{K}^{+}$ conductance (e.g., opposite effects of cAMP on ion channels have been recorded in other monoaminergic systems [116]).

\section{DOPAMINE-AN ALTERNATIVE CHOICE, THE CHOICE OF ALTERNATIVES}

The principle is that an increase of DA activity promotes the likelihood of switching between alternative sources of information. The act of switching may increase the probability of a new input to a given brain region influencing the output and/or result in an ongoing input being shut off from influencing the output (cf. Fig. 2). The effect is likely to be seen either in the change of the temporal patterning of a behavioral sequence or in the initiation of new responses. Thus what one will observe at the behavioral level after DA activity changes will depend crucially on the prevailing response tendencies in the individual as well as on basal DA activity levels.

For evidence I shall present examples from studies of the organization of simple and more complex sequences of responding, from studies of sensory, cognitive and motivational organization. This evidence is presented to support, firstly, the hypothesized switching effect, secondly, the likelihood of this effect being generalizable across DA systems, and, thirdly, to provide a contrast between the modulatory effects of DA and NA activity.

\section{Some Methodological Problems}

All of the points mentioned in the context of NA studies have some relevance for DA studies, but some of these bear elaboration for the understanding of studies of DA systems.

(1) Brain lesions. The warning that electrolytic (E-L) damage of structures containing $\mathrm{CA}$ neurons can and will affect neighbouring cells using different transmitters, justified in principle for NA nuclei, reaches major significance for DA studies. Time and again, electrolytic damage of the VTA has produced opposite behavioral results to those resulting from 6-OHDA damage (e.g., hyper- vs. no locomotion changes $[127,135]$; facilitated vs. impaired active avoidance acquisition $[135,199]$ respectively).

(2) 6-OHDA effects. (a) The dose is important [127]. Earlier studies produced a wider ranging series of results than those of the last 3-4 years, when doses became more standardized. (b) DA levels following lesion are often checked, but not necessarily in a wide enough range of relevant struc- tures (cf. controversy over the contribution of DA in the cortex or N. accumbens to induced hyperlocomotion [33, $115,219])$. (c) Even if DA levels following brain lesions are found to be decreased, often neither turnover (levels of metabolites) nor receptor assays (neuroleptic binding) are undertaken to verify hypo- or hyper-function in the DA system. Thus increased $D_{1}$ stimulated activity and $D_{2}$ binding can be found in some (prefrontal) areas and not in other projection regions (e.g., $\mathrm{N}$. accumbens) using E-L and 6-OHDA techniques that do decrease levels of DA and DOPAC in the same regions [267].

(3) Drug action. Studies of DA activity rely heavily on the state-of-the-art understanding of the mode of action of drugs-a level of understanding that is often thin and often not taken into account by many groups (e.g., presynaptic/autoreceptor effects of neuroleptics at low doses [223] and the purported predominant effect of low doses of amphetamine on DA rather than NA systems [229]).

\section{A Case for Dopaminergic Modulation by Switching and Initiating Behavioral Activity}

"Switching" - that can mean between item or input A and $B$ (see Fig. 2), between program $x$ and $y$. It can also mean that with $B$ in control, a new program or behavior will be initiated. The influence of $A$ is switched off, for a moment or for a period. Without a switching capability the influence of $\mathrm{C}$ may never be initiated.

Consider the profound impairments-the abilities that can be considered switched off or not initiated following lesions at one of the sources of an ascending DA system. Bilateral lesions of the SN with 6-OHDA can produce aphagia, adipsia, akinesia and a loss of coordinated responses to sensory stimuli $[155,158,279]$. The latter along with the major impairments of the acquisition of simple approach or conditioned avoidance responses [67] seem to reflect an inability to initiate or to organize the appropriate motor response [291,301]. After bilateral lesions of the VTA with 6-OHDA, rats perform two or three times worse on a delayed alternation task than they did when first faced with the task [257]; while escaping from signalled foot-shock in a two-way active avoidance task quite well, they may show but one avoidance response in 200 or more trials [199]; food-hoarding [121] and parental-nursing behavior [74] may virtually disappear. Clearly a small number of mesencephalic cells seem to be involved in a wide range of behavioral organization. Further, if their function drops out ( $>90 \%$ DA depletion [42]) the results may be disastrous for the individal. This is in marked contrast to the results of damage to the NA system.

In most, if not in all, cases the impairment is not a primary one. The animal can be helped to move or to eat (in the former instance) to learn or recall simple discriminations (in the latter instance). This would seem to imply a modulatory action for DA rather than an all-or-none mediating role. Let us take one example [60].

Rats were trained to rotate, in some cases to the left, in others to the right, in order to obtain a reward of sugar solution (FR 2). Large unilateral 6-OHDA lesions were placed just rostral to the $\mathrm{SN}$ (DA<6\% in striatum and $\mathrm{N}$. accumbens). Postoperatively a postural bias proved transient. Contralateral, but not ipsilateral, lesions completely blocked turning. (DA utilization increases in the $\mathrm{N}$. accumbens and decreases in the $\mathrm{SN}$ contralateral to the trained turning direction [300].) On the rare occasions that the animals did turn, the movement was "smooth and rapid in either direc- 

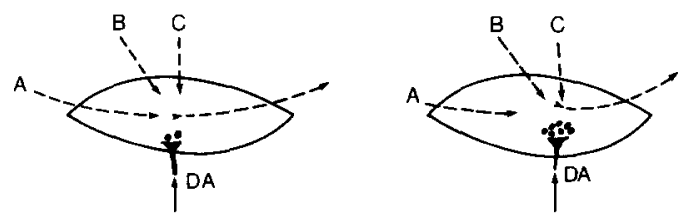

LOW DA ACTIVITY

HIGH DA ACTIVITY $\begin{array}{ll}\text { Input A likely to maintain Probability increased that iffout } C \\ \text { control over outaut. } & \text { (B) gains control of output. }\end{array}$

Assumption

no change in nature of inputs $A$, B orC

FIG. 2. A schematic representation of a brain region receiving dopaminergic (DA) input and information from three sources (A, B and C). Where there is a low level of DA activity (left) the probability is low that the control of the output by input $A$ will be changed: where the level of DA activity increases (right) the probability that input from $B$ or $C$ will influence the output increases. This change of control increases the probability that the behavior influenced by the output will also change.

tion." When required to reverse their response, this group showed no problems. But the original "ipsilateral" group could not acquire the reversal. It thus seems that the motor, learning and motivational capacities of these animals remained, to a large degree, intact. What was missing, as the authors conclude, was the initiation of voluntary action. This echoes the function of initiation (rather than a fundamental motor disability [67]) as was postulated for the N. accumbens (a major mesolimbic DA projection region) just 7-8 years previously [109].

However, if DA activity does not simply represent a "Go" (or "stop") signal, one must consider studying what happens in the terminal regions as well as in the cells of origin; one must consider situations where behavior may change (A to B) as well as its on- or offset (Fig. 2).

I propose to consider the organization of responses at three levels of complexity - a component, a pattern and a sequence of behavior. In the first category are elements such as limb movements (e.g., walking and lever pressing). The second category consists of responses of the whole organism (e.g., to feed, drink, rear, visit alleys). The most complex level of organization is the behavioral sequence or strategy that may require a cognitive plan for its organization (e.g., search for food, for safety and working memory in complex, changing environments).

DA activity is highly correlated with the occurrence of a large number of response components: strains of mice with more DA cells in the midbrain and higher tyrosine hydroxylase activity show more amphetamine-stimulated activity, locomotion and rearing in the open field [68]; the more basal locomotor activity one rat shows over another, the higher the DA content in the $N$. accumbens [40]. It is primarily, though not exclusively, here that hyperlocomotion is brought about by DA release (e.g., amphetamine) or manipulation of DA receptor activity (e.g., lesions) (e.g., N. accumbens [40,109,114, 123]; septum [31]; less so in the caudate, or amygdala [110]; controversial in frontal cortex $[33,115,269]$; not in the tuberculum olfactorium [110]). The application of DA to the SN-VTA of mice produces a spiroperidol-reversible depression of locomotor activity [24].

As already indicated, unilateral asymmetric DA activity increases the probability of turning contralateral to the side showing higher activity, whether this activity is spontaneous or elicited (review [80]). Vertical activity or rearing, like turning, may be elicited by a variety of factors, but increases of DA activity (particularly in the $\mathrm{N}$. accumbens) are prominent among them $[152,198,202,203,230]$.

This line of argument may be extended to the performance of operant (e.g., lever press) responses. On a fixed ratio (FR) schedule of reinforcement, an animal is encouraged to initiate many responses to maximize reward and to inhibit this tendency on a DRL schedule (differential reinforcement for low rates of responding). On the FR schedule, the number of lever responses emitted is directly proportional to the increment of the DA conversion index following ${ }^{3} \mathrm{H}$ tyrosine administration [99]. This operant related increase of DA turnover (also found on variable interval schedules) has been noted in the striatum, amygdala and hypothalamus [102] and is accompanied by significant pargyline-induced depletions of DA metabolites (DOPAC and HVA [101]).

Where differential responding is required, it is not surprising that the administration of DA or amphetamine to the ventro-anterior striatum decreases response efficiency [189]. It had earlier been suggested [145] that such an effect could be explained by an impairment of the selection or switching between alternative response sequences. This interpretation was raised again to explain why 6-OHDA treatment of the ventro-lateral striatum resulted in peaks of responding on a DRL 20 schedule either at very short $(4 \mathrm{sec})$ or much longer intervals $(22-24 \mathrm{sec})$ [61].

This last result seems to show that after local DA depletion animals can discriminate time but could be deficient in the temporal organization of responding. The other results, that superficially relate to an increased volume or frequency of behavior with increased DA activity, could be explained by DA mediating a "go" signal for simple motor programs or facilitating switching between small groups of cells that organize the components of the response. Some motor behavior can undoubtedly be realized through the mobilization of "response programs." However, the limb-specific movements and postures that arise from different types of basal ganglia pathology, ranging from dyskinesias to choreoathetosis suggest that in voluntary behavior, a constellation of cell groups, is often responsible for the coordination of different response components. Indirect experimental support for this comes from the conditioned leg flexion paradigm [297]. Conditioned flexion in cats was suppressed by stimulation of the $N$. accumbens and enhanced by lesions. The result was interpreted in terms of gating the limbic control of pallidal output.

Let us now move to a higher level of response organization where the pattern of choice and response provides a stronger test for the switching hypothesis. If rats receive a pellet of food every $60 \mathrm{sec}$ (FI60) in a compartment where there is a water dispenser, they will acquire the habit of drinking in excess. Animals with free access to food and water may (over the same period) eat eight times as much but drink only $60 \%$ of the volume drunk on the test schedule. This adjunctive drinking is attenuated by depletion of DA in the $N$. accumbens [231]. This treatment does not affect eating and drinking as such, but affects the time sharing between these activities. There is no evidence that treated rats showing the same response timing as controls will lick less during the response. This renders interpretations in terms of an effect on response vigour unlikely. Thus the effect is not a matter of the mere volume of behavior nor is it similar to that of NA on the signal to noise ratio. Indeed, if adjunctive drinking is established before the chemical lesion, the effect 
of DA depletion is to attenuate the frequency of switching and to prolong the time in which adjunctive behavior is shown [230]. Similar results with this schedule induced polydipsia as well as with adjunctive wheel running have been recently reported [289]. (Recently an unpublished study [266] recorded increased adjunctive drinking after 6-OHDA lesion of the septum. In view of the role of the septohippocampal system in attention and learning [192] it may be that these animals were deficient in switching away from the environmental elements controlling the acquisition of the habit. However, the fact that electrical stimulation of the septum can suppress drinking behavior [83] makes this result difficult to interpret.)

In this experiment, the effect of DA depletion in the $\mathrm{N}$. accumbens may be viewed as a perseveration of the tendency imposed by pre-experimental experience. If the experience is irrelevant, less adjunctive drinking is seen; if the animal has developed the habit, it will drink more on the post-lesion test. This interpretation is compatible with the view that the $N$. accumbens may contribute the motivational component to the system that initiates or brings a response pattern into action $[109,230]$.

In an examination of response-switching, Evenden and Robbins [64] trained rats to respond to two locations where each was reinforced according to a random schedule. There was no advantage of a strategy for repeating over one for alternating responses. Amphetamine-treated animals, at a range of lower doses $(<2 \mathrm{mg} / \mathrm{kg})$, increased the amount of response switching. This result resembles the alternation between two of three alleys shown by amphetamine-treated rats in an unreinforced Y-maze $[125,203]$. However, unlike the exploratory situation, Evenden and Robbins found that at high doses this tendency reversed (see penultimate section). Their study neatly eliminated several alternative explanations of the amphetamine effect, such as activity changes, rate dependency, impaired discrimination and response cost by repeating the test in situations requiring different response topography (e.g., Skinner box with/without walls between the levers and hole-poke responses where no locomotion was required).

These authors have also shown [63] that amphetamine reduced the effect of reinforcement on choice through a decrease of the repetition of a reinforced win-stay and an increase of the non-reinforced lose-stay strategy. These studies did not attempt to show that the effect of amphetamine was due to changes of DA activity (but cf. "methodological problems"). Although an interpretation in terms of switching most easily fits their results, an alternative hypothesis invoking tuning mechanisms could be put forward to explain the exploratory situation (cf. the proposal of a NA-mediated attentional change to explain changes of unrewarded $Y$-maze alley-choice [125]).

In an independent series of studies, the idea for a role for DA in the control of switching arose from observations on the way rats learn to find four food-containing holes in an arena with 16 holes $[193,194,196]$. Over repeated trials, animals develop an individual preferred sequence (strategy) for visiting the food holes and avoiding the empty ones [200]. After 100 trials, a preferred strategy is repeated 7-9 times in a session of 10 trials. During the test the neuroleptic, spiroperidol was injected into the VTA. (Neuroleptic blocking of autoreceptors in the VTA can increase mesolimbic DA activity and here increased the utilization of DA in the $N$. accumbens [199].) Such animals managed to repeat a strategy two or three times at most [198]. An increase of switch- ing between responses [194] was also reflected by an increase of rearing [198]. Similar increases of collateral behavior interrupting ongoing sequences of behavior have been observed after treatments that release DA $[191,203]$ and result in hypersensitive DA systems [57, 254, 257]. By contrast, depletion of DA in the $\mathrm{N}$. accumbens was reported to result in the persistence of exploratory strategies (Berlyne box and novel object [202]) and the persistence of an acquired drinking preference (one of three available drinking burettes [230]).

With the acquisition of complex behavioral preferences and food-search strategies, the discussion has reached the third level of response organization and planning. Cools [39] has presented a striking example with the choice of "lifesaving" strategies shown by rats placed in a basin of water. Observation of apomorphine-treated animals in danger of drowning showed that they shifted their ongoing behavior as soon as they had repeated a particular item once or twice in vain. Controls would repeat an item perhaps three times but, by contrast, haloperidol-treated animals restricted their repertoire to just one item. Such animals often had to be rescued. (Rats with 6-OHDA lesions of the striatum or VTA have been reported to be able to find an escape platform hidden beneath the surface of a milk-filled arena, albeit with delayed latencies [92]. It is not evident, however, that escape strategies were analysed. Cools has also noted that haloperidol-treated animals, when they brushed the escape rope, would climb out. Thus there is no major disagreement between these studies. Recently a Swedish study found that 6-OHDA lesioned rats (later treated with striatal grafts) showed an initial deterioration of their platform-finding strategy, as might have been expected (Brundin personal communication).) Other studies by Cools have also shown that behavioral sequences are sensitive to DA interactions in the neostriatum $[180,281]$. Further, the activity of such mechanisms may be influenced by stimulation and inhibition of septal DA activity (cf. collateral connections under "Anatomical considerations" earlier in this article). Another brain region that seems to be crucially involved in the elaboration and coordination of behavioral strategies is the habenula. This region receives an impressive convergence of projections (striatal limbic and dopaminergic [211,212]). Large lesions here also markedly reduce the number of types of behavior and the number of behavioral repetitions shown in a series of swimming and "lifesaving" tests [272]. Neither study found that their treatments incurred sensory neglect or gross motor impairments.

DA activity can undoubtedly affect higher cognitive functions related to perception, learning and memory. Rarely are the results, presented merely in terms of latency or accuracy of response, amenable to interpretation in terms of switching (or tuning). A seductive example, however, is a perceptual task that was presented to human subjects. A figure, The Schröder Staircase, was presented at three levels of ambiguity. One may entertain two mutually exclusive percepts-to view the stairs from above or below. Under chlorpromazine, a DA antagonist, the time for entertaining the preferred percept increased. Switching between percepts decreased [96].

In conclusion, the sum of this evidence suggests that the switching-timing hypothesis for DA modulation of activity in different projection areas has explanatory power. Still stronger tests of the hypothesis combining neurophysiological and behavioral techniques (as with the NA system) remain to be carried out. 
The DA Involvement in Information Processing: Similarities and Differences to NA Actions

If the modulatory action of DA is to be distinguished from that for NA, it is useful to briefly compare and contrast the apparent role of DA in situations parallel to those described in the section on secondary evidence for a tuning function for NA.

A contribution to vigilance or arousal is indicated by the responsivity of VTA-SN cells to light, sound, tactile and noxious stimuli $[13,134,151,276]$. The responses to stimulation often lasted longer than those seen in projection areas, but many of the cells did not show the characteristics of DA cells. Of those that did, $70 \%$ were suppressed [151].

Unilateral brain damage can result in a lack of responsiveness to all modes of stimulation presented contralaterally. This is particularly clear for structures innervated by fibers arising from the SN. Sensory neglect has been observed in many species after damage to the SN $[4,278]$, the MFB [154,159], striatum [108,182], amygdala [118,277] and the frontal cortex $[48,103]$. But since the syndrome produced by 6-OHDA lesions is aggravated by electrolytic damage, there seems to be a significant contribution to the syndrome from non-DA neurons [156]. Part of the sensory neglect syndrome may reflect an inability to initiate the stimulus appropriate response [291].

Bilateral treatments (e.g., DA to amygdala [110]; 6-OHDA to the VTA [75], or the frontal cortex [33]) do not produce striking changes of exploratory behavior, but more subtle changes such as changes of frequency and duration of the investigation of holes in a holeboard [75,196]. After 6-OHDA treatment of the $\mathrm{N}$. accumbens, rats will visit the new compartment of a Berlyne box and make contact with a novel object [202]. But the change of behavior in response to changes in the new situation is very slow. Together these results suggest that after unilateral damage, behavior is controlled by the dominant intact side (switch on), but after bilateral damage there may be problems in time sharing of responses (hole exploration), switching or changing strategies (Berlyne box) or in the motivation to initiate a response $[157,181,230]$.

It is difficult to summarize the large literature on the effect of the manipulation of DA activity on learning [165]. Electrolytic damage of the VTA may exaggerate a 6-OHDA induced syndrome or produce opposite effects. An exaggerated impairment is seen on delayed alternation learning $[256,257]$; learning an active avoidance task in a shuttle box may be facilitated [135] after E-L or prevented after 6-OHDA lesion [199]. These examples illustrate, firstly, that interpretations must take into account the methods used and, secondly, that both positively and negatively reinforced task performance can be affected. In contrast to studies of the LC, reports of learning impairments are widespread after damage of the SN (e.g., E-L [270]) and VTA (e.g., 6-OHDA [221]). These tasks involved brightness discriminations and passive avoidance.

A large number of reports have shown that treatment with DA antagonists impairs active avoidance acquisition, but not the initiation of escape responses. Perhaps it is not surprising that electrical stimulation of the SN encourages animals to step down in a passive avoidance task (cf. $[13,16])$. Here are impairments on two tasks with opposite requirements produced by two appropriately opposite treatments. It may be appropriate within the context of specific DA systems to interpret these effects, as Beninger does [16], in terms of a role for DA in incentive motivational learning, it is important to note that the level of interpretation in this article reflects the treatment of channels of information in any DA system (cf. DNAB vs. VNAB). An explanation in terms of switching is not exclusive. For example, the impaired latent learning reported for rats treated during their exposure with the DA agonist apomorphine [1] can be viewed as having involved inappropriate incentive conditioning to the blind alleys (as in [16]) or from the point of view that this manipulation was hardly appropriate for stabilizing the information flow between channels (cf. Fig. 2). Most of these studies do not present their results in a form that either weakens or supports the switching hypothesis.

Stimulus choice can be disrupted, as indicated by an attenuation of the phenomena of latent inhibition or conditioned blocking, by a variety of treatments that change DA activity in different regions (e.g., chronic amphetamine, haloperidol; acute amphetamine to the $\mathrm{N}$. accumbens; 6-OHDA to the frontal cortex and septum $[21,43,199,258,259,293]$, Oades in preparation). All of these treatments may have increased DA activity in one region or another, but it is impossible to be definitive on this point as these studies reported either receptor supersensitivity or increased DA utilization (not both) in one or at most a few brain regions. However, in contrast to similar studies with the NA system, these results are more easily assimilated into the switching hypothesis for DA (e.g., the promotion of switching between different information-processing channels, cf. also [148]).

In these learned inattention studies, as well as those of reversal and extinction, there is a tendency (stronger than for NA systems) for brain-region-specific biases to appear (cf. the different nature and distribution of collateral branching in the two CA systems, see introduction). For example, animals with 6-OHDA lesions of the $\mathrm{N}$. accumbens require twice as many trials as controls to acquire a reversal of a T-maze spatial learning task; animals with 6-OHDA lesions of the septum show a marked but transient $(5 \mathrm{~min})$ overresponding on extinction of a continuously reinforced lever response (the remaining extinction curve is similar to controls) [266]. These results are compatible with a switching and/or time-sharing interpretation of DA function, respectively, in separate parts of the mesolimbic system.

There are indications from drug studies for a DA role in working memory (radial maze [14]), reference memory (holeboard [195]) and the retrieval of memory (inhibitory avoidance [2]), although a major impairment of memory is not found after chemical lesion of ascending DA systems $[196,257]$. Many possibilities for the interpretation of such results in terms of mechanism remain open. It would be interesting to have some direct evidence for the influence of DA activity on tasks requiring a serial search through memory (e.g., Sternberg item recognition task).

The proposed role for DA is not restricted to a putative role in attention and learning (nor a role limited to the nigrostriatal or mesolimbic systems). Eating and drinking (motivated) responses are influenced by changes of DA activity in the septum and amygdala [83, 100, 136]. Other activities based on specific motivational states such as hoarding or nursing are impaired or abolished by 6-OHDA treatments of the VTA $[74,121]$. The biphasic effects of low and high doses of apomorphine on locomotion (mesolimbic) and stereotypy (mesostriatal) are also recorded for penile erection, latency to ejaculate and the postejaculatory refractory period $[36,41]$. These studies implicate a contribution from diencephalic DA systems. An example has been discussed by 
Robbins and Everitt ([230], cf. [27]). The reproductive behavior of female rats consists of active proceptive (courting) responses that alternate with the passive lordotic posture. A decrease of DA activity lowers the levels of the latter while enhancing the former. According to the authors it is the pattern of switching between the one and the other that changes. The effect does not seem similar to an NA role in tuning or biassing the input/output relations.

There are therefore numerous studies of DA activity in different organizational systems of the CNS which support the hypothesis that DA has a modulatory role different from that shown by NA. If these studies do not directly support interpretations for or against the proposed role of switching, initiation and timing, they are often compatible with the proposal.

\section{On a Neuronal Mechanism}

Of several possible accounts of the effect of DA on neuronal mechanisms, one parallels that for NA involving two receptors, one of which is coupled with adenylate cyclase $\left(D_{1}\right)$. Like NA, DA is usually "inhibitory"-depressing the firing of extracellularly recorded neurons in the hippocampus $[20,245]$ and the caudate nucleus $[8,124]$. These are the two regions most investigated with intracellular recording techniques that will be described below.

In the hippocampal slice preparation the application of DA (superfusion and microtopical) results in a hyperpolarization dependent on a $\mathrm{Ca}^{2+}$ activated increase in the $\mathrm{K}^{+}$ conductance $[18,19,90]$. (Population responses recorded extracellularly are suppressed.) This is accompanied by a decrease of membrane resistance, in the amplitude of responses to hyperpolarizing pulses and of the frequency of spontaneous depolarizations and spikes [90]. $\mathrm{Cl}^{-}$injection has no effect on this, thus demonstrating the difference from GABA mechanisms $[18,19]$. The DA antagonist, cis-afluphenthixol, is relatively specific for the $D_{1}$-adenylate cyclase mechanism [242] present in the hippocampus [56]. This agent blocked the induced hyperpolarization $[18,19]$. By contrast application of DA and cAMP increased and lengthened the hyperpolarization that typically follows the burst firing of these cells. The normally relatively short hyperpolarization (c. $3 \mathrm{~min}$ ) is followed (c. $10 \mathrm{~min}$ ) by a long-lasting depolarization with increased membrane resistance. During this stage afferent (Schaffer) volleys are more effective for spike generation. A profound potentiation of population responses can last for hours [90]. This study found this latter effect to be depressed by spiroperidol (possible $\mathrm{D}_{2}$ mechanism).

These results demonstrate a mechanism whereby, if the $D_{1}$ and $D_{2}$ sites prove to be physiologically significant in vivo, could alter the timing of hippocampal burst firing $[18,19]$ and hence potentially affect central activity and behavioral organization.

Although it may be premature to counterpoint these findings, in vitro, with others from the caudate, in vivo, the latter also demonstrate an unusual mechanism. Here iontophoresis of DA resulted in depolarization and an increase of membrane resistance that was independent of $\mathrm{Na}^{+}$mechanisms. But, uniquely, this depolarization was accompanied by depressed firing rates $[17,106]$. (This is in contrast to cholinergic mechanisms, for example.) The amplitude of this "excitatory" effect was reduced by fluphenazine [106] and chlorpromazine [124]. These agents affect both $D_{1}$ and $D_{2}$ sites [242]. But the $\mathrm{D}_{2}$ receptor may just be the more numerous of the two in the neostriatum [241]. Importantly it was noted that although the application of DA resulted in the suppression of firing elicited by previous administration of glutamate $[25,106]$, if the glutamate was applied during the depolarization plateau, the cell fired [106]. This provides a potentially important mechanism for controlling the timing of the effects of cortical input on central activity. (One recent study [25] found no effect of DA on the response to cortical driving but the position of the pipette relative to the cell body and the cortical synapse may explain this.)

These results indicate that it is possible for DA to have opposite effects on membrane properties-effects that may depend on two receptor types. Herrling, who studied both the hippocampus and caudate nucleus in vivo $[105,106]$ found hyperpolarization to be the dominant response from the former (where $D_{1}$ binding sites are strongly represented) and depolarization dominant in the latter (where $D_{2}$ sites are strongly represented). In view of the relatively minor DA projection to the hippocampus, one should not lose sight of the possibility that pharmacological manipulations may be demonstrating binding sites for DA-active drugs rather than physiologically active DA neuronal receptors and that neurophysiological studies may be demonstrating $C A$ rather than specific DA properties. But both of the DA-effects have been reported from studies of the mammalian superior cervical ganglion and from invertebrates $[11,106]$. Both effects could take place on the same neuron. Studies of other structures tend to vindicate results obtained from the hippocampal model. Nonetheless the implications for hippocampal function itself should be treated cautiously.

On moving the site of iontophoresis from the outer dendrites closer to the axon hillock Herrling found an increased number of cells in the caudate that showed hyperpolarization responses to DA, which were faster in onset than the depolarizations [106]. However, the two effects could be competitive. Prolonged application of DA could reverse the hyperpolarization into a depolarization. (Only depolarizations were recorded from injection sites close to the cell body by Brown and Arbuthnott [25].) The problem for the site of injection did not occur for the in vitro studies. But the results of the in vivo work should be interpreted with caution in view of the difficulty to control for the input to the structure under study and in the present reports uncertainty over the influence of the state of the animal on the recordings obtained.

The idea that activity at both $\mathrm{D}_{1}$ and $\mathrm{D}_{2}$ sites (on a neuronal element, dendrite or afferent terminal) could affect one and the same neuron is not new. The destruction of cell bodies in the SN destroyed the $D_{2}$, but left the $D_{1}$ receptors intact $[76,204]$. Further, a recent study of the striatum conducted in vitro found that $D_{2}$ agonists could inhibit the increased efflux of cAMP caused by $D_{1}$ agonists in a noncompetitive way and in the absence of $\mathrm{Ca}^{2+}$ ions [261]. This seems to show not only the opposite effects of the two receptors but suggests that both could be found on the same neuron.

If one attempts precision over the receptor mechanism, at present, one enters the realm of speculation. Recently the combination of pharmacological and neurophysiological techniques have produced reasons to suggest the presence of 4 receptors-of $D_{2}$ and $D_{3}$ receptors on cortical and nigral afferents to the striatum which may be opposed postsynaptically by $D_{4}$ and $D_{1}$ intrinsically located receptors $[25,41]$. The argument is open as to whether we are talking of multiple receptor types or merely conformational changes of two receptors. Either way, some of the results obtained are still 
consistent with a switching effect in terms of the transmission of information [41]. A recent extracellular recording study illustrates this consistency in practice on information flow and additionally underlines the difference with NA mechanisms [153]. The fimbria were stimulated to evoke field and unitary responses in the lateral septum. Iontophoresis of NA strongly inhibited responses (a decrease of the number of action potentials per fimbria-stimulus). By contrast application of DA produced excitation in some units, inhibition in others (consistent with different loci for receptor types) and some cells showed bimodal changes. These results are of interest as they refer to CA effects on the activity in a specific pathway and not simply on spontaneous unit responses.

In conclusion, DA neurons possess a number of features that would seem to suit their role in some sort of modulatory function (e.g., high resistance, long time constant, low safety factor, electronic coupling and burst firing [85-87]). Potential mechanisms that could underlie the so-called switching effect of DA would seem to be present in proscribed projection regions of the CNS (e.g., hyper-, depolarizing and bimodal responsiveness, two differentially distributed receptor types, release of large "packets" of DA (cf. $500 \mathrm{msec}$ ) [87]). It remains for further study to see what the anatomical and neuronal distribution of the different binding sites may be and what rules may determine the normal interaction of physiological effects at the two principle sites. As with the elucidation of NA mechanisms, the distribution of transmitter-linked adenylate cyclase activity may be an important indicator.

\section{Problems for Interpretation}

There are two major types of problem in the proposals for two types of modulation shown by NA and DA. Firstly, how would one predict "what results" from "which situation"- $a$ priori, what is the criterion for when tuning or switching would be expected and recognized. Secondly, how does one reconcile results that appear on the surface to contradict the hypothesis-a posteriori, what are the limits to imposing an interpretation favourable to expectations on the data. Clearly the two problems overlap and, particularly the latter, must be resolved by further experiment.

The first problem may be approached by attempting to understand what purpose is served by having two CA modulated mechanisms. One explanation, put forward in the context of exploratory behavior [97], may have wider application. Exploratory behavior is initiated when the redundancy of a situation changes from low to high. There is a necessary adaptation to allow the processing of incongruous stimuli (cf. rearing in the rat). Indeed an infusion of NA into the hippocampus produces an increase of rearing and of divergent exploration in the form of the reconnaissance of the new area [70]. In the opposite instance (e.g., swimming escape strategy) there is an urgent need for change and selection of the appropriate channel for information processing (and action). (Where incentive is important this may also incur rearing.) For the rapid change and selection DA is involved and a switching-initiation mechanism is needed. In between lie many situations where there is a role for both mechanismsfor tuning where associations need to be acquired between stimulus events or between stimulus events and, say, mnesic traces (a comparator); for switching, where the serial testing of alternatives (responses, hypotheses, mnesic traces) or where urgency and timing may play a significant role.
Clearly the failure to tune or to incur too much switching may lead to a similar state of responsiveness in an animal facing changing environmental circumstances, even if the underlying neurobiological mechanism is different. It is not a paradox to consider that there are situations where the "role" of the two systems, as opposed to the "function" of specific brain regions, may overlap. If for reasons of significance and incentive, there is an advantage in increasing the volume of behavior (e.g., ICSS responding), both switching and tuning may be helpful in different components of the NA and DA systems.

For a large number of reports there is no easy a priori criterion with which to judge whether switching, say, has or has not occurred. For example, rats treated with the CA precursor L-DOPA gave up their first incorrect strategy on a reversal learning task sooner than controls. They then persevered with a position habit [243]. Another study reported that marmosets, treated with amphetamine "changed their motor responses and stimulus choice in order to preserve the acquired reward value or meaning of certain stimuli" [226]. In both studies, both persistence and switching were described. Without further data and neurobiological intervention, one may only speculate on the role NA stimulation and DA activation played.

If an experimental design is to be chosen to try to distinguish the two modulatory roles, then more data must be recorded than the simple latency for and accuracy of performance (e.g., on retrieval tasks). It is useful to employ tasks where several possibilities for response are available and to record the different types of error (e.g., perseverative, false positive or working memory errors), concomitants of choice behavior (e.g., collateral activity) and strategies fcorrect or false sequences). It would be advantageous to contrast the effects of stimulation with the elimination of transmitter activity, to apply pharmacological agents locally in different projection regions, to use partial agonists/antagonists and to record receptor and turnover changes in several regions and finally, where possible, to use in vivo electrophysiological recording techniques.

In relation to the second problem, one might, in some controversial cases, attempt a posteriori explanations with reference to other studies. Thus a working hypothesis for future test can be advanced. I shall briefly illustrate this with two well-known controversial phenomena that, at first sight, pose difficulties for the proposed DA role in switching.

In the first instance, although low doses of amphetamine appear to promote the probability of switching, higher doses in the rat $(2 \mathrm{mg} / \mathrm{kg})$ produce repetitive, often stereotyped behavior [72]. The second instance relates to the existence of perseverative symptoms of schizophrenia that are sometimes attributed to hyperdopaminergic function (discussion in [197]) and compared to symptoms arising in chronic amphetamine psychosis [38]. Both phenomena may be explained by activity in other transmitter systems-high doses of amphetamine can affect NA and serotonergic activity and the endogenous psychoses undoubtedly reflect imbalances in several systems. But I shall illustrate how the switching hypothesis generates a testable alternative in terms of DA activity.

Low doses of amphetamine promote the release of DA that in turn promotes the probability of switching occurring postsynaptic to the DA terminal. But this effect is shortlasting. Almost at the same time a depression of firing may be recorded electrophysiologically $[26,66]$ and a depression of the electrochemical signal for the intraneuronal metabo- 
lite, DOPAC, is claimed to be registered $[66,144]$. This apparent decrease of DA activity may be the result of autoinhibition from the excess of amphetamine-stimulated release of DA. Whereas at low doses of amphetamine, the extraneuronal metabolite, HVA, tends to decrease in concentration, levels of HVA increase following higher doses of amphetamine [132]. As this increase may be recorded postmortem after high doses of amphetamine, it suggests that there is a longer lasting increase of DA turnover.

The postsynaptic effect is that after a low dose of amphetamine there are moments when an alternative input to the system has a chance to influence the output, but if DA activity is raised for a longer period the system may be continually biassed to the normally suppressed input. In other words, the switch between inputs to the locus under consideration has become locked in favor of the one that would, under normal circumstances, not control the output. Hence in the presence of appropriate stimuli (and in appropriate organismal states) stereotypes can recur (e.g., sniffing and gnawing in the rat [72], grooming or hand-staring in the monkey [227]).

Thought disturbed schizophrenics may suffer from ideational perseveration or from associative intrusions and distraction. Some of these symptoms are sensitive to treatments of the dopaminergic system (cf. [197]). Neuroleptics, particularly atypical neuroleptics, improve indices of thought disturbance [253]. It should be pointed out that the two extremes of these symptoms are usually reported from different subjects. In such cases, an explanation parallel to that for amphetamine (previous paragraph) can be used. Such subjects might be expected to have an above normal sensitivity to the DA system [208]. (Positive and negative opinions still appear over the extent to which increased $B_{\max }$ and $K_{D}$ for $\mathrm{DA}$ in schizophrenic patients reflects the treatment and/or the condition, see $[146,147,224]$.) Between subjects one might expect a difference showing a more chronic and higher level of DA activity in those showing perseveration than those showing intrusions. Where the characteristics appear in the same individual they may be attributable to circadian changes of DA activity [28,29], modulators (e.g., hormones) affecting DA sensitivity ([32], perhaps receptors [117]) or to states (e.g., stress) that affect DA metabolism [22,237]. The balance between the extremes of the symptoms would reflect the difference I have described for low and high doses of amphetamine to animals. Indeed the apparent statedependency of the therapeutic effects of amphetamine in some schizophrenic subjects supports this interpretation [282].

Finally I should re-emphasize a point noted earlier. The behavior that follows a given dose of amphetamine or that will be observed in a schizophrenic patient with a putative DA disorder will depend both on basal levels of DA activity and the individual-specific frequency of the acts measured during behavioral testing. The resolution of the aforegoing controversies will only be resolved by further and more detailed observation and study.

\section{CONCLUSIONS}

\section{Evidence Required}

No single experiment has been, or will be, performed to confirm or disprove the tuning and switching hypotheses for CA function. Conclusions will be based on the sum of the evidence. This sum must include more behavioral studies after specific toxin damage. The interim conclusions of these studies must be compared to those resulting from electrophysiological (and pharmacological) stimulation of NA and DA pathways. These have been surprisingly neglected. Cross-checking with the aid of biochemical analysis techniques of the effects on CA utilization (metabolite/CA) and receptors in many brain regions is becoming essential for the interpretation of the role of a "quiet" or "active" pathway and even for determining which pathway is responsible. At the neuronal level, hypotheses remain speculative in the absence of more detailed evidence on the distribution of the receptor types both between brain regions and on a single neuron. Is it possible for one receptor type to dominate in one locus and, if more of one type are present, is it possible for only one to be physiologically activated? Here a better understanding of the rules underlying the effects of adenosine (for NA and DA) and guanine (for DA) nucleotide activity on conductance would help.

In studies of NA a closer examination of its role in the play-off between two or more stimuli that compete for response control is required to confirm current tuning proposals. Close attention should be given to controlling the nature and salience of the different stimuli and deciding if performance is well- or merely partially-learned. These points are important for future work, as a tuning system is only likely to show itself if the animal has not committed itself, decided and selected what to do in an ongoing situation.

The DA story lacks an elegant cooperative study using behavioral and neurophysiological techniques (contrast NA). Such a study would be nicely complemented by in vivo electrochemical registration of DA turnover during task performance. With current developments records may soon be taken from particular brain regions during tasks when behavior would be expected to change and switches of neuronal activity might be predicted to occur. Particularly important evidence could be obtained by recording from DA regions, say, in the absence, through lesion, of an effective NA system. Several types of search task might be suitable-where search may be taken as the key-word for attention-related processes in cued vs. non-cued tasks (e.g., holeboard and sample-matching tasks) as well as retrieval in, for example, a Sternberg item recognition type of task. In learned inattention tasks it would be valuable to know more about the effects of stimulation of septal and entorhinal DA projections on dentate neurons, perforant path activity and performance.

In the long term two sine-qua-non developments are needed. Firstly, NA and DA systems should be studied by the same authors in the same experiment. (This occurs in neurophysiological but seldom in behavioral studies.) Secondly, the results of the CA studies must be compared and contrasted with those of other transmitters. It may well be that no transmitter carries "the message." They are all "modulators": only the detailed constitution of the nerve terminal environment conveys specificity of function.

\section{Evidence Obtained}

Clear evidence exists to show that CA activity exerts a modulatory rather than a specific role both within one functional domain and across different CNS systems. Further the result of NA activity is not the same as for DA activity. Beyond this generalization-have the proposals for a role for NA and DA in tuning and switching, respectively, matured?

I believe supportive evidence has accumulated faster than the difficulties posed by controversial findings. The level of 
explanation attempted is illustrated by the question-what happens to the information flow from diverse sources to a population of neurons when $\mathrm{CA}$ is released there? Differences between the systems may be expected alone from the different patterns of ramification of NA and DA neurons: the former system branches widely between brain regions whereas the latter often shows a nest-like innervation of small constellations of cells.

Both systems are active when environmental stimuli impinge on the organism and, in contrast to other transmitter systems (e.g., 5-HT [275]), this activity tends to be restricted to waking states. This implies an importance of CA function for adaptation to changing circumstances. Changes of vigilance states alone cannot account for the different consequences of NA and DA depletion on learning and motivation. NA depletion often leads to subtle changes such as the delay to reach criterion or the attainment of a poor learning criterion. It is as if the appropriate biassing of information processing is disturbed, the attribution of relative significance to inputs is impaired, the comparator function between two or more possibilities is quantitatively inefficient. The effect of NA depletion or activity depends on whether a decision for response has or has not been made (well- vs. partially-learned responding) (cf. cortical neuronal responsiveness, "blocking," extinction effects). DA depletion can produce both abrupt or little change. Depending on the individual level of DA activity and ongoing frequency of a behavioral pattern depletion results in a difficulty to initiate (e.g., move/explore) or to switch between environmentally appropriate behavioral sequences (e.g., eat/drink, motivates search).

At the neuronal level appropriate mechanisms for two types of modulation exist. These include the possibility for disinhibition, hyper- and de-polarizing effects with at least two types of receptor on or impinging on a single neuron. In NA systems there can be a potentiation of excitation thresholds (in one dimension) or of signal flow (e.g., hippocampal burst firing) in the time dimension. $D_{1}$ and $D_{2}$ receptor-activation can affect the timing of burst firing in the hippocampus and the switching or timing of the influence of inputs to the striatum.

One of the important features of these studies lies with the way ideas have crossed between different branches of investigation and found a measure of support. Over the last 5-10 years, there have been developments in the methods of study and the subject of study. The principles described relate to the way systems act and to the mechanisms controlling the flow of information and not to a region-specific organizational "function." The impact of these studies will depend on further careful analysis and differentiation of when a system is locked or flexible, when relevant information is tuned out. For the DA system more direct tests of the switching hypothesis are required. For the NA system a better understanding of the extraordinary plasticity of the system would alleviate may controversies. Only when these issues have received further attention may one get an insight to the nature of the dysfunction of such mechanisms in a range of psychomotor disorders.

\section{ACKNOWLEDGEMENTS}

I am grateful to Drs. G. Stock and S. Ahlenius for their helpful discussion of an earlier draft of these ideas and to the referees for their comments on the later manuscript. I also thank the Max Planck Gesellschaft, the Fyssen Foundation and NATO (senior fellowship) for financial support at different stages of the preparation of this review.

\section{REFERENCES}

1. Ahlenius, S., J. Engel and M. Zoller. Effects of apomorphine and haloperidol on exploratory behavior and latent learning in mice. Physiol Psychol 5: 290-294, 1977.

2. Altman, H. J. and D. Quartermain. Facilitation of memory retrieval by centrally administered catecholamine stimulating agents. Behav Brain Res 7: 51-63, 1983.

3. Amaral, D. G. and H. M. Sinnamon. The locus coeruleus: neurobiology of a central noradrenergic nucleus. Prog Neurobiol 9: 147-196, 1977.

4. Anden, N-E., A. Dahlström, K. Fuxe and K. Larsson. Functional role of the nigro-neostriatal dopamine neurones. Acta Pharmacol Toxicol 24: 263-274, 1966.

5. Anden, N-E., K. Fuxe, B. Hamberger and T. Hökfelt. A quantitative study of the nigro-neostriatal dopamine neurone system in the rat. Acta Physiol Scand 67: 306-312, 1966.

6. Anlezark, G. M., T. J. Crow and A. P. Greenway. Impaired learning and decreased cortical norepinephrine after bilateral locus coeruleus lesions. Science 181: 682-684, 1973.

7. Antelman, S. M. and A. R. Caggiula. Norepinephrinedopamine interactions and behavior. Science 195: 646-653, 1977.

8. Archer, T. DSP 4 (N-2-chloroethyl-N-ethyl-2-bromobenzylamine) a new noradrenaline neurotoxin and stimulus conditions affecting acquisition of two way active avoidance. J Comp Physiol Psychol 96: 476-490, 1982.

9. Archer, T., A. K. Mohammed and T. U. C. Järbe. Latent inhibition following systemic DSP 4: effects due to presence and absence of contextual cues in taste aversion learning. Behav Neural Biol 38: 287-307, 1983.
10. Ashford, J. and B. J. Jones. The effects of intra-amygdaloid injections of 6-hydroxydopamine on avoidance responding in rats. Br J Pharmacol 56: 255-261, 1976.

11. Aston-Jones, G. Modulation of spontaneous and sensory evoked discharge of locus coeruleus neurons by behavioral state: Functional implications. Contribution to EBBS workshop. In: Brain Plasticity, Learning and Memory, edited by $P$. Schmitt and B. Will. To be published, 1985.

12. Aston-Jones, G. and F. Bloom. Norepinephrine-containing locus coeruleus neurones in behaving rats exhibit pronounced responses to non-noxious environmental stimuli. J Neurosci 1: $887-900,1981$.

13. Barasi, S. Responses of substantia nigra neurons to noxious stimulation. Brain Res 171: 121-130, 1979.

14. Beatty, W. M. and J. R. Rush. Spatial working memory in rats: Effects of monoaminergic antagonists. Pharmacol Biochem Behav 18: 7-12, 1983.

15. Beaudet, A. and L. Descarries. The monoamine innervation of rat cerebral cortex: synaptic and non-synaptic axon terminals. Neuroscience 3: 851-860, 1978.

16. Beninger, R. J. The role of dopamine in locomotor activity and learning. Brain Res Rev 6: 173-196, 1983.

17. Bernardi, G., M. G. Marciani, C. Morocutti, F. Pavone and P. Stanzione. The action of dopamine on rat caudate neurons intracellularly recorded. Neurosci Lett 8: 235-240, 1978.

18. Bernardo, L. S. and D. A. Prince. Dopamine modulates a $\mathrm{Ca}^{2+}$-activated potassium conductance in mammalian hippocampal pyramidal cells. Nature 297: 76-79, 1982. 
19. Bernardo, L. S. and D. A. Prince. Dopamine action on hippocampal pyramidal cells. $J$ Neurosci 2: 415-423, 1982.

20. Biscoe, T. J. and D. W. Straughan. Micro-electrophoretic studies of neurones in the cat hippocampus. $J$ Physiol 183: $341-359,1966$.

21. Bignami, G., V. Giardini and E. Alleva. Treatment behaviour interactions in activity/habituation and avoidance: state changes and pre-exposure to CS, US and drug. Experimental Analysis of Behaviour Meeting, Liège 1983, unpublished manuscript.

22. Bliss, E. L. and J. Ailion. Relationship of stress and activity to brain dopamine and homovanillic acid. Life Sci 10: 1161-1169. 1971.

23. Bloom, F. E. Is there a neurotransmitter code in the brain? In: Advances in Pharmacology and Therapeutics, vol 2, Neurotransmitters, edited by P. Simon. Oxford: Pergamon Press, 1979, pp. 205-213.

24. Bradbury, A. J., B. Costall and R. J. Naylor. Reduction of motor responding of the mouse by actions of dopamine agonists in the midbrain. Neuropharmacology 22: 1171-1176, 1983.

25. Brown, J. R. and G. W. Arbuthnott. The electrophysiology of dopamine $\left(D_{2}\right)$ receptors: a study of the actions of dopamine in corticostriatal transmission. Neuroscience 10: 349-355, 1983.

26. Bunney, B. S., G. K. Aghajanian and R. H. Roth. L-DOPA, amphetamine and apomorphine: comparison of effects on firing of rat dopaminergic neurones. Nature 245: 123-125, 1973.

27. Caggiula, A. R., J. G. Herndon, R. Scanlon, D. Greenstone, W. Bradshaw and D. Sharp. Dissociation of active from im mobility components of sexual behavior in female rats by central 6-hydroxydopamine: implications for CA involvement in sexual behavior and sensorimotor responsiveness. Brain Res 172: 505-520, 1979 .

28. Cahill, A. L. and C. F. Ehret. Circadian variations in the activity of tyrosine hydroxylase, tyrosine aminotransferase and tryptophan hydroxylase: relationship to catecholamine metabolism. $J$ Neurochem 37: 1109-1115, 1981.

29. Campbell, A., M. Herschel, B. Sommer, J. R. Madsen, B. M Cohen and R. J. Baldessarini. Circadian changes in the distribution and effects of haloperidol in the rat. Neuropharmacology 21: 663-669, 1982.

30. Carli, M., T. W. Robbins, J. L. Evenden and B. J. Everitt. Effects of lesions to ascending noradrenergic neurones on performance of a 5-choice serial reaction task in rats: implications for theories of dorsal noradrenergic bundle function based on selective attention and arousal. Behav Brain Res 9: 361-380, 1983

31. Carey, R. J. Septal lesions augment locomotor hyperactivity induced by amphetamine and not scopolamine. Psychopharmacology (Berlin) 76: 96-97, 1982.

32. Carroll, B. J. Limbic system-adrenal cortex regulation in depression and schizophrenia. Psychosom Med 38: 106-121, 1982.

33. Carter, C. J. and C. J. Pycock. Behavioural and biochemical effects of dopamine and noradrenaline depletion within the medial prefrontal cortex of the rat. Brain Res 192: 163-176. 1980.

34. Charney, D. D. and D. E. Redmond. Neurobiological mechanisms in human anxiety: evidence supporting central noradrenergic hyperactivity. Neuropharmacology 22: 1531-1536, 1983.

35. Chu, N. S. and F. E. Bloom. The catecholamine-containing neurons in the cat dorso-lateral pontine tegmentum: distribution of the cell bodies and some axonal projections. Brain Res 66: $1-21,1974$

36. Clark, J. T., M. L. Stefanick, E. R. Smith and J. M. Davidson. Further studies on alterations in male rat copulatory behavior induced by the dopamine receptor agonist RDS-127. Pharmacol Biochem Behav 19: 781-786, 1983.

37. Clark, T. K. The locus coeruleus in behavioral regulation: evidence for behavior specific versus general involvement. Behav Neural Biol 25: 271-300, 1979.
38. Connell, P. Amphetamine Psychosis. London: Chapman and Hall, 1958.

39. Cools, A. R. Role of neostriatal dopaminergic activity in sequencing and selecting behavioural strategies: facilitation of processes involved in selecting the best strategy in a stressful situation. Behav Brain Res 1: 361-378, 1980.

40. Costall, B., S-G. Hui and R. J. Naylor. The basal locomotor activities of rats dictate the intensity of behavioural change following mesolimbic denervation. Neurosci Lett Suppl 5: 461 1980.

41. Costentin, J., I. Dubuc and P. Protais. Behavioral data suggesting the plurality of central dopamine receptors. Adv Biochem Psychopharmacol 37: 289-297, 1983.

42. Creese, I. and S. D. Iversen. The pharmacological and anatomical substrates of the amphetamine response in the rat. Brain Res 83: 419-436, 1975.

43. Crider, A., P. R. Solomon and M. A. McMahon. Disruption of selective attention in the rat following chronic d-amphetamine administration: relationship to schizophrenic attention disorder. Biol Psychiatry 17: 351-361, 1982.

44. Crow. T. J. and S. Wendlandt. Impaired acquisition of a passive avoidance response after lesions induced in the locus coeruleus by 6-OH-dopamine. Nature 259: 42-44, 1976.

45. Crow. T. J., J. F. W. Deakin, S. E. File, A. Longden and S Wendlandt. The locus coeruleus-noradrenergic systemevidence against a role in attention, habituation, anxiety and motor activity. Brain Res 155: 249-261, 1978.

46. Crutcher, K. A. and J. N. Davis. Hippocampal and $\beta$-adrenergic receptors: comparison of ${ }^{3}(\mathbf{H})$ dihydroalprenol and ${ }^{3}(\mathrm{H})$ WB 4101 binding with noradrenergic innervation in the rat. Brain Res 182: 107-117, 1980.

47. Dahlström, A. and K. Fuxe. Evidence for the existence of monoamine containing neurons in the central nervous system. I Demonstration of monoamines in the cell bodies of brain stem neurons. Acta Physiol Scand Suppl 232: 1-55, 1964

48. Damasio, A. R., H. Damasio and H. C. Chui. Neglect following damage to frontal lobe or basal ganglia. Neuropsychologia 18: $123-132,1980$.

49. Davies, D. C., G. Horn and B. J. McCabe. Changes in telencephalic catecholamine levels in the domestic chick. Effects of age and visual experience. Dev Brain Res 10: 251-255, 1983.

50. Davis, M. Neurochemical modulation of sensory-motor reactivity: acoustic and tactile startle reflexes. Neurosci Biobehav Rev 4: 241-263, 1980.

51. Davis, M., J. M. Cedarbaum, G. K. Aghajanian and D. S. Gendelman. Effects of clonidine on habituation and sensitization of acoustic startle in normal, decerebrate and locus coeruleus-lesioned rats. Psychopharmacology (Berlin) 51: 243-253, 1977.

52. Delini-Stula, A., E. Mogilnicka, C. Hann and D. J. Dooley. Novelty-oriented behavior in the rat after selective damage of locus coeruleus projections by DSP-4, a new noradrenergic neurotoxin. Pharmacol Biochem Behav 20: 613-618, 1984.

53. De Montigny, C., R. Y. Wang, T. A. Reader and G. K. Aghajanian. Monoaminergic denervation of the rat hippocampus: microiontophoretic studies on pre- and post-synaptic supersensitivity to norepinephrine and serotonin. Brain Res 200: $363-367,1980$

54. Descarries, L., K. C. Watkins and Y. Lapierre. Noradrenergic axon terminals in the cerebral cortex of the rat. III: Topometric ultrastructural analysis. Brain Res 133: 197-222, 1977.

55. Divac, I. Carefully with Occam's razor. Trends Neuresci 5: 451. 1982.

56. Dolphin, A. and J. Bockaert. $\beta$-Adrenergic receptors coupled to adenylate cylcase in cat brain: regional distribution, pharmacological characteristics and adaptive responsiveness. In: Recent Advances in the Pharmacology of Adrenoreceptors. edited by U. Szabadi, C. M. Bradshaw and P. Bevan. Amsterdam: North Holland Biomedical Press, 1981. 
57. Donovick, P. J., R. G. Burright, R. J. Fanelli and W. J. Engellenner. Septal lesions and avoidance behavior: Genetic, neurochemical and behavioral considerations. Physiol Behav 26: 495-507, 1981.

58. Dragunow, M. and R. Laverty. Failure of dorsal bundle lesions in rats to increase distractibility to a low intensity tone. Pharmacol Biochem Behav 18: 673-675, 1983.

59. Driscoll, P., J. Dedek, J. R. Martin and B. Zivkovic. Twoway avoidance and acute shock stress induced alterations of regional noradrenergic, dopaminergic and serotonergic activity in Roman high- and low-avoidance rats. Life Sci 33: 1719-1725, 1983.

60. Dunnett, S. B. and A. Björklund. Conditioned turning in rats: dopaminergic involvement in the initiation of movement rather than the movement itself. Neurosci Lett 41: 173-178, 1983.

61. Dunnett, S. B. and S. D. Iversen. Neurotoxic lesions of ventrolateral but not anteromedial neostriatum in rats impair differential reinforcement of low rates (DRL) performance. Behav Brain Res 6: 213-226, 1982.

62. Dunwiddie, T. V., A. L. Mueller, P. C. Bickford and N. R. Zahniser. Electrophysiological and biochemical sequelae of the destruction of hippocampal noradrenergic afferents by DSP-4. Brain Res 269: 311-317, 1983.

63. Evenden, J. L. and T. W. Robbins. Dissociable effects of d-amphetamine, chlordiazepoxide, and $\alpha$-fluphenthixol on choice and rate measures of reinforcement in the rat. Psychopharmacology (Berlin) 79: 180-186, 1983.

64. Evenden, J. L. and T. W. Robbins. Increased response switching, perseveration and perseverative switching following d-amphetamine in the rat. Psychopharmacology (Berlin) 80: $67-73,1983$.

65. Everitt, B. J., T. W. Robbins, M. Gaskin and P. J. Fray. The effects of lesions to ascending noradrenergic neurons on discrimination learning and performance in the rat. Neuroscience 10: 397-410, 1983.

66. Ewing, A. G., K. D. Alloway, S. D. Curtis, M. A. Dayton, R. M. Wightman and G. V. Rebec. Simultaneous electrochemical and unit recording measurements: characterization of the effects of d-amphetamine and ascorbic acid on neostriatal neurons. Brain Res 261: 101-108, 1983.

67. Fibiger, H. C., A. G. Phillips and A. P. Zis. Deficits in instrumental responding after 6-hydroxydopamine lesions of the nigro-neostriatal dopaminergic projection. Pharmacol Biochem Behav 2: 87-96, 1974.

68. Fink, J. S. and D. J. Reis. Genetic variations in midbrain dopamine cell number: parallel with differences in responses to dopaminergic agonists and in naturalistic behaviors mediated by central dopaminergic systems. Brain Res 222: 335-349, 1981.

69. Flexner, J. B., L. B. Flexner and A. C. Church. Studies of memory: the cerebral spread on an engram in mice as affected by inhibitors of dopamine- $\beta$-hydroxylase. Pharmacol Biochem Behav 18: 519-523, 1983.

70. Flicker, C. and M. A. Geyer. Behavior during hippocampal microinfusions. I. Norepinephrine and diversive exploration. Brain Res Rev 4: 79-103, 1982.

71. Foote, S. L., R. Freedman and A. P. Oliver. Effects of putative transmitters on neuronal activity in monkey auditory cortex. Brain Res 86: 229-242, 1975.

72. Fray, P. J., B. J. Sahakian, T. W. Robbins, G. F. Koob and S. D. Iversen. An observational method for quantifying the behavioural effects of dopamine agonists: contrasting effects of d-amphetamine and apomorphine. Psychopharmacology (Berlin) 69: 253-259, 1980.

73. Freedman, R., B. J. Hoffer, D. J. Woodward and D. Puro. Interaction of norepinephrine with cerebellar activity evoked by mossy and climbing fibers. Exp Neurol 55: 269-288, 1977.

74. Gaffori, O. and M. Le Moal. Disruption of maternal behavior and appearance of cannibalism after ventral mesencephalic tegmentum lesions. Physiol Behav 23: 317-343, 1979.
75. Gaffori, O., M. Le Moal and L. Stinus. Locomotor hyperactivity and hypoexploration after lesion of the dopaminergic A 10 area in the ventral mesencephalic tegmentum (VMT) of rats. Behav Brain Res 1: 313-329, 1980.

76. Gale, K., A. Guidotti and E. Costa. Dopamine-sensitive adenylate cyclase: Localization in the substantia nigra. Science 195: 503-505, 1977.

77. German, D. C. and D. M. Bowden. Catecholamine systems as the neural substrate for intracranial self-stimulation: a hypothesis. Brain Res 73: 381-419, 1974.

78. German, D. C., D. S. Schlüsselberg and D. J. Woodward. Three dimensional computer reconstruction of midbrain dopaminergic neuronal populations: from mouse to man. $J$ Neural Transm 57: 243-254, 1983.

79. Geyer, M. A., D. S. Segal and A. J. Mandel. Opposite behavioral effects produced by locus coeruleus and median raphe lesions. Soc Neurosci Abstr 2: 488, 1976.

80. Glick, S. D. and D. A. Ross. Lateralization of function in the rat brain. Trends Neurosci 4: 196-199, 1981.

81. Gold, P. E. and J. L. McGaugh. Hormones and memory. In: Neuropeptide Influences on the Brain and Behavior, edited by L. H. Miller, C. A. Sandman and A. J. Kastin. New York: Raven Press, 1977, pp. 127-143.

82. Gold, P. E. and S. F. Zornetzer. The mnemon and its juices: neuromodulation of memory processes. Behav Neural Biol 38 151-190, 1983.

83. Gordon, F. J. and A. K. Johnson. Electrical stimulation of the septal area in the rat: prolonged suppression of water intake and correlation with self-stimulation. Brain Res 206: 421-430, 1981.

84. Gottfries, C-G., R. Adolfsson, A-M. Aquilonius, A. Carlsson, S-A. Eckernäs, A. Nordberg, L. Oreland, L. Svennerholm, A. Wiberg and B. Winblad. Biochemical changes in dementia disorders of Alzheimer type (AD/SDAT). Neurobiol Aging 4: 261-271, 1983.

85. Grace, A. A. and B. S. Bunney. Intracellular and extracellular electrophysiology of nigral dopaminergic neurons-1 Identification and characterization. Neuroscience 10: 301-315, 1983.

86. Grace, A. A. and B. S. Bunney. Intracellular and extracellular electrophysiology of nigral dopaminergic neurons-2 Action potential generating mechanisms and morphological correlates. Neuroscience 10: 317-331, 1983.

87. Grace, A. A. and B. S. Bunney. Intracellular and extracellular electrophysiology of nigral dopaminergic neurons-3 Evidence for electrotonic coupling. Neuroscience 10: 333-348, 1983.

88. Gray, J. A. The Neuropsychology of Anxiety: An Enquiry into the Functions of the Septo-Hippocampal System. Oxford: OUP, 1982.

89. Gray, J. A., J. Feldon, J. N. P. Rawlins, S. Owen and N. McNaughton. The role of the septo-hippocampal system and its noradrenergic afferents in behavioural responses to nonreward. In: Functions of the Septo-Hippocampal System. edited by K. Elliott and J. Whelan. Amsterdam: Elsevier, 1978, pp. 275-307.

90. Gribkoff, V. K. and J. H. Ashe. Modulation by dopamine of population responses and cell membrane properties of hippocampal CA 1 neurons in vitro. Brain Res 292: 327-338, 1984.

91. Haas, H. L. and A. Konnerth. Histamine and noradrenaline decrease calcium-activated potassium conductance in hippocampal pyramidal cells. Nature 302: 432-434, 1983.

92. Hagan, J. J., J. E. Alpert, R. G. M. Morris and S. D. Iversen. The effects of central catecholamine depletions on spatial learning in rats. Behav Brain Res 9: 83-104, 1983.

93. Hamburg, M. D. and R. P. Cohen. Memory access pathway: Role of adrenergic versus cholinergic neurons. Pharmacol Biochem Behav 1: 295-300, 1973.

94. Han, M. F. and P. J. Livesey. Brightness discrimination learning under conditions of cue enhancement by rats with lesions in the amygdala or hippocampus. Brain Res 125: 277-292, 1977. 
95. Harik, S. I. Locus ceruleus lesion by local 6-hydroxydopamine infusion causes marked and specific destruction of noradrenergic neurons, long-term depletion of norepinephrine and the enzymes that synthesize it and enhanced dopaminergic mechanisms in the ipsilateral cerebral cortex. $J$ Neurosci 4 : 699-707, 1984

96. Harris, J. P. and O. T. Phillipson. Chlorpromazine reduces the perceptual ambiguity of a reversible visual figure. Neuropharmacology 20: 1337-1338, 1981.

97. Harrison-Read, P. E. Evoked potential correlates of stable interindividual differences in rat behavior. Brain Res Bull 4: $447-451,1979$

98. Hedreen, J. P. and J. P. Chalmers. Neuronal degeneration in rat brain induced by 6-hydroxydopamine: a histological and biochemical study. Brain Res 47: 1-36, 1972.

99. Heffner, T. G. and L. S. Seiden. Synthesis of catecholamines from ${ }^{3} \mathrm{H}$-tyrosine in brain during the performance of operant behavior. Brain Res 183: 403-419, 1980.

100. Heffner, T. G., J. A. Hartman and L. S. Seiden. Feeding increases dopamine metabolism in the rat brain. Science 208: $1168-1170,1980$.

101. Heffner, T. G., G. Vosmer and L. S. Seiden. Increased transport of 3,4-dihydroxyphenylacetic acid from brain during performance of operant behavior in the rat. Brain Res 293: 85-91, 1984.

102. Heffner, T. G., D. Luttinger, J. A. Hartman and L. S. Seiden. Regional changes in brain catecholamine turnover in rat during performance on fixed ratio and variable interval schedules of reinforcement. Brain Res 214: 215-218, 1981.

103. Heilman, K. M. and E. Valenstein. Auditory neglect in man. Arch Neurol 22: 260-264, 1972.

104. Henke, P. G. Dissociation of the frustration effect and the partial reinforcement extinction effect after limbic lesions in rats. $J$ Comp Physiol Psychol 91: 1032-1038, 1977.

105. Herrling, P. L. The membrane potential of cat hippocampal neurons recorded in vivo displays four different reaction mechanisms to iontophoretically applied transmitter agonists. Brain Res 212: 331-343, 1981.

106. Herrling, P. L. and C. D. Hull. Iontophoretically applied dopamine depolarizes and hyperpolarizes the membrane of cat caudate neurons. Brain Res 192: 441-462, 1980.

107. Isaacson, R. L., W. J. Street, T. D. Petit and A. J. Dunn. Neonatal treatment with 6-OHDA affects brain NE content but not behavior. Physiol Psychol 5: 49-52, 1977.

108. Iversen, S. D. Striatal function and stereotyped behaviour. In: Psychobiology of the Striatum, edited by A. R. Cools, A. H. M. Lohman and J. H. L. Van den Bercken. Amsterdam: North Holland Biomedical Press, 1978, pp. 99-118.

109. Iversen, S. D. and G. F. Koob. Behavioral implications of dopaminergic neurons in the mesolimbic system. Adv Biochem Psychopharmacol 16: 209-214, 1977.

110. Jackson, D. M., N-E. Anden and A. Dahlström. A functional effect of dopamine in the nucleus accumbens and in some other dopamine rich parts of the rat brain. Psychopharmacologia 45: $139-149,1975$.

111. Jahr, C. E. and R. A. Nicoll. Noradrenergic modulation of dendrodendritic inhibition in the olfactory bulb. Nature 297: 227-229, 1982.

112. Jerlicz, M., W. Kostowski, A. Bidzinski and M. Hauptmann. Effects of lesions in the ventral noradrenergic bundle on behavior and response to psychotropic drugs in rats. Pharmacol Biochem Behav 9: 721-724, 1978.

113. Jones, B. E. and L. Friedman. Atlas of catecholamine perikarya, varicosities and pathways in the brainstem of the cat. J Comp Neurol 215: 382-396, 1983.

114. Jones, D. L., S. L. Berg, R. L. Dorris and R. E. Dill. Biphasic locomotor response to intra-accumbens dopamine in a nonhuman primate. Pharmacol Biochem Behav 15: 243-246, 1981.

115. Joyce, E. M., L. Stinus and S. D. Iversen. Effect of 6-OHDA into either nucleus accumbens septi or frontal cortex on spontaneous and drug-induced activity. Neuropharmacology 22: $1141-1145,1983$
116. Kaczmarek, L. R. and F. Strumwasser. Net outward currents of bag cell neurons are diminished by a cAMP analogue. $S_{i x}$ Neurosci Abstr 7: 932. 1981

117. Kafka, M. S., A. Wirz-Justice, D. Naber, R. Y. Moore and M. A. Benedito. Circadian rhythms in rat brain neurotransmitter receptors. Fed Proc 42: 2796-2801, 1983.

118. Karadi, Z., L. Lenard and Z. Hahn. Comparison of perceptual deficits caused by unilateral pallidal and amygdala chemical lesions in rats. E.B.B.S (Parma), Abstr., p. 88, 1982.

119. Kasamatsu, T. and P. Heggelund. Single cell responses in cat visual cortex to visual stimulation during iontophoresis of noradrenaline. Exp Brain Res 45: 317-324, 1982.

120. Kayama, Y., T. Negi, M. Sugitani and K. Iwama. Effects of locus coeruleus stimulation on neuronal activities of dorsal lateral geniculate nucleus and perigeniculate reticular nucleus of the rat. Neuroscience 7: 655-666, 1982.

121. Kehr, W. 3-Methoxytyramine and normetanephrine as indicators of dopamine and noradrenaline release in mouse brain in vivo. I Neural Transm 50: 165-178, 1981.

122. Kelley, A. E. and L. Stinus. Disappearance of hoarding behavior after 6-hydroxydopamine lesions of the mesolimbic dopamine neurons and its reinstatement with L-DOPA. Behav Neurosci, in press.

123. Kelly, P. H., O. W. Seviour and S. D. Iversen. Amphetamine and apomorphine response following 6-OHDA lesions in $\mathrm{n}$. accumbens and corpus striatum. Brain Res 74: 507-522. 1975.

124. Kitai, S. T., M. Sugimori and J. D. Kocsis. Excitatory nature of dopamine in the nigro-caudate pathway. Exp Brain Res 24: $351-363,1976$.

125. Kokkinidis, L. and H. Anisman. Amphetamine models of paranoid schizophrenia: an overview and elaboration of animal experimentation. Psychol Bull 88: 551-579, 1980.

126. König. N., J. J. Serrano, A. Szafarczyk and D. Demêmes. Role of catecholamines in nervous system development: effects of prenatal 6-hydroxydopa treatment on behaviour and brain structures. Monogr Neural Sci 9: 11-19, 1983.

127. Koob, G. F., L. Stinus and M. Le Moal. Hyperactivity and hypoactivity produced by lesions to the mesolimbic dopamine system. Behav Brain Res 3: 341-359, 1981

128. Kostowski, W. Interactions between serotonergic and catecholaminergic systems in the brain. Pol J Pharmacol Pharm 27: suppl. 6, 15-24, 1975.

129. Kostowski, W. and A. Plaznik. Facilitation of conditioned avoidance behavior in rats with lesioned ventral noradrenergic bundle. Acta Physiol Pol 509: 6-29, 1978.

130. Kostowski, W., M. Jerlicz, A. Bidzinski and M. Hauptmann. Behavioral effects of neuroleptics, apomorphine and amphetamine after bilateral lesions of the locus coeruleus in rats. Pharmacol Biochem Behav 7: 289-293, 1977.

131. Kovacs, G. L., D. H. G. Versteeg, E. R. de Kloet and B. Bohus. Passive avoidance performance correlates with catecholamine turnover in discrete limbic brain regions. Liff Sci $\mathbf{2 8}$ : $1109-1116,1981$.

132. Kuczenski, R. Amphetamine-haloperidol interactions on striatal and mesolimbic tyrosine hydroxylase activity and dopamine metabolism. J Pharmacol Exp Ther 215: 135-142. 1980 .

133. Leconte, P. and E. Hennevin. Post-learning paradoxical sleep reticular activation and noradrenergic activity. Physiol Behav 26: $587-594,1981$

134. Le Moal, $M$. and $M$. Olds. Peripheral auditory input to the midbrain limbic area and related structures. Brain Res 167: 1-17. 1979.

135. Le Moal, M., B. Cardo and L. Stinus. Influence of ventral mesencephalic lesion on various spontaneous and conditioned behaviors in the rat. Physiol Behav 4: 567-573, 1969.

136. Lenard, L., Z. Hahn and Z. Karadi. Body weight changes after neurochemical manipulations of lateral amygdala: noradrenergic and dopaminergic mechanisms. Brain Res 249: 95-101. 1982.

137. Lindvall, $\mathrm{O}$. and A. Björklund. The organization of the ascending catecholamine neuron systems in the rat brain. Acta Physiol Scand Suppl 412: 1-48, 1974. 
138. Lindvall, $O$. and A. Björklund. Anatomy of the dopaminergic neuron system in the rat brain. Adv Biochem Psychopharmacol 19: $1-23,1978$.

139. Lindvall, O., A. Björklund and I. Divac. Organization of dopamine neurons projecting to neocortex and septum. $A d v$ Biochem Psychopharmacol 16: 39-46, 1977.

140. Livingstone, M. and D. Hubel. Effects of sleep and arousal on the processing of visual information in the cat. Nature 291: $554-561,1981$.

141. Lorden, J. F., E. J. Rickert and D. W. Berry. Forebrain monoamines and associative learning. I. Latent inhibition and conditioned inhibition. Behav Brain Res 9: 181-199, 1983.

142. Lorden, J. F., E. J. Rickert, R. Dawson and M. A. Pelleymonater. Forebrain norepinephrine and the selective processing of information. Brain Res 190: 569-573, 1980.

143. Loughlin, S. E. and J. H. Fallon. Substantia nigra and ventral tegmental area projections to cortex: topography and collateralization. Neuroscience 11: 425-435, 1984.

144. Louilot, A. Effet de divers traitements pharmacologiques sur le métabolisme de la dopamine dans le noyau accumbens et le tubercule olfactif: utilisation de la voltammétrie in vivo. Thèse de 3rd Cycle: Université de Bordeaux, 1983.

145. Lyon, M. and T. W. Robbins. The action of central nervous system drugs: a general theory concerning amphetamine effects. In: Current Developments in Psychopharmacology, vol 2, edited by W. Essman and L. Valzelli. New York: Spectrum Press, 1975, pp. 81-163.

146. Mackay, A. V. P. High dopamine in the left amygdala. Trends Neurosci 7: 107-108, 1984.

147. Mackay, A. V. P., L. L. Iversen, M. Rossor, E. Spokes, E. Bird, A. Arregui, I. Crees and S. H. Snyder. Increased brain dopamine and dopamine receptors in schizophrenia. Arch Gen Psychiatry 39: 991-997, 1982.

148. Mackintosh, N. A theory of attention: variations in the associability of stimuli with reinforcement. Psychol Rev 82: 276$298,1975$.

149. Madar, Y. and M. Segal. The functional role of the noradrenergic system in the visual cortex: activation of the noradrenergic pathway. Exp Brain Res 41: A14, 1980.

150. Madison, D. V. and R. A. Nicoll. Noradrenaline blocks accommodation of pyramidal cell discharge in the hippocampus. Nature 299: 636-638, 1982.

151. Maeda, H. and G. J. Mogenson. Effects of peripheral stimulation on the activity of the neurons in the ventral tegmental area, substantia nigra and midbrain reticular formation of rats. Brain Res Bull 8: 7-14, 1982.

152. Makanjuola, R. O. A., G. Hill, R. C. Dow, G. Campbell and G. W. Ashcroft. The effects of psychotropic drugs on exploratory and stereotyped behavior of rats studied on a holeboard. Psychopharmacology 55: 67-74, 1977.

153. Marchand, J. E. and N. Hagino. Effects of iontophoretically applied norepinephrine and dopamine on fimbria evoked activity in the lateral septum. Exp Neurol 82: 683-697, 1983.

154. Marshall, J. F. and P. Teitelbaum. Further analysis of sensory inattention following lateral hypothalamic damage in rats. $J$ Comp Physiol Psychol 86: 375-395, 1974.

155. Marshall, J. F. and P. Teitelbaum. New considerations in the neuropsychology of motivated behaviors. In: Handbook of Psychopharmacology, vol 7, edited by L. L. Iversen, S. D. Iversen and S. H. Snyder. New York: Plenum Press, 1977, pp. 201-229.

156. Marshall, J. F., N. Berrios and S. Sawyer. Neostriatal dopamine and sensory inattention. J Comp Physiol Psychol 94: $833-846,1980$.

157. Marshall, J. F., D. Levitan and E. M. Stricker. Activationinduced restoration of sensorimotor functions in rats with dopamine-depleting brain lesions. J Comp Physiol Psychol 90: 536-546, 1976.

158. Marshall, J. F., J. S. Richardson and P. Teitelbaum. Nigrostriatal bundle damage and lateral hypothalamic syndrome. $J$ Comp Physiol Psychol 87: 808-830, 1974.
159. Marshall, J. F., B. M. Turner and P. Teitelbaum. Sensory neglect produced by lateral hypothalamic damage. Science 174: 523-525, 1971.

160. Martin, P. R., H. Weingartner, E. K. Gordon, R. S. Burns, M. Linnoila, I. J. Kopin and M. H. Ebert. Central nervous system catecholamine metabolism in Korsakoff's psychosis. Ann Neurol 15: 184-187, 1984.

161. Martin-Iverson, M., M. Pisa, E. Chan and H. C. Fibiger. Enhanced neophobia but normal plasma corticosterone levels in rats with dorsal noradrenergic bundle lesions. Pharmacol Biochem Behav 17: 639-643, 1982.

162. Mason, S. T. Noradrenaline: Reward or extinction? Neurosci Biobehav Rev 3: 1-10, 1979.

163. Mason, S. T. Noradrenaline and selective attention: a review of the model and the evidence. Life $S_{c i}$ 27: 617-631, 1980.

164. Mason, S. T. Noradrenaline in the brain: progress in theories of behavioral function. Prog Neurobiol 16: 263-303, 1981.

165. Mason, S. T. Catecholamines and Behaviour. Cambridge: Cambridge University Press, 1984.

166. Mason, S. T. and H. C. Fibiger. Altered exploratory behavior after 6-OHDA lesion to the dorsal noradrenergic bundle. $\mathrm{Na}$ ture 269: 639-643, 1977.

167. Mason, S. T. and H. C. Fibiger. Noradrenaline and spatial memory. Brain Res 156: 382-386, 1978.

168. Mason, S. T. and H. C. Fibiger. Evidence for a role of brain noradrenaline in attention and stimulus sampling. Brain Res 159: $421-426,1978$.

169. Mason, S. T. and H. C. Fibiger. Regional topography within noradrenergic locus coeruleus as revealed by retrograde transport of horseradish peroxidase. J Comp Neurol 187: 703-724, 1979.

170. Mason, S. T. and S. D. Iversen. Learning in the absence of forebrain noradrenaline. Nature 258: 422-424, 1975.

171. Mason, S. T. and S. D. Iversen. Effects of selective forebrain noradrenaline loss on behavioural inhibition in the rat. J Comp Physiol Psychol 91: 165-173, 1977.

172. Mason, S. T. and S. D. Iversen. Central and peripheral noradrenaline and resistance to extinction. Physiol Behav 20: 681686,1978

173. Mason, S. T. and S. D. Iversen. Theories of the dorsal bundle extinction effect. Brain Res Rev 1: 107-137, 1979.

174. Mason, S. T. and D. Lin. Dorsal noradrenergic bundle and selective attention.J Comp Physiol Psychol 94: 819-832, 1980.

175. Mason, S. T., C. Wood and A. Angel. Brain noradrenaline and varieties of alternation learning. Behav Brain Res 9: 119-127, 1983.

176. Mason, S. T., D. C. S. Roberts and H. C. Fibiger. Noradrenaline and neophobia. Physiol Behav 21: 353-361, 1978.

177. Mason, S. T., R. Q. J. King, P. Banks and A. Angel. Brain noradrenaline and anaesthesia: behavioral and electrophysiological evidence. Neuroscience 10: 177-185, 1983.

178. McCormick, D. A. and R. F. Thompson. Locus coeruleus lesions and resistance to extinction of a classically conditioned response: Involvement of the neocortex and hippocampus. Brain Res 245: 239-249, 1982.

179. McEntee, W. J. and R. G. Mair. Memory impairment in Kor sakoff's psychosis: a correlation with brain noradrenergic activity. Science 202: 905-907, 1978.

180. Megens, A. A. P. H. and A. R. Cools. Involvement of the septum in central dopamine-acetyl choline interaction in morphine-treated cats. Pharmacol Biochem Behav 18: 761767,1983

181. Mesulam, M-M. A cortical network for directed attention and unilateral neglect. Ann Neurol 10: 309-325, 1981.

182. Mettler, F. A. and C. C. Mettler. The effects of striatal injury. Brain 65: 242-255, 1942.

183. Mishkin, M. Memory in monkeys severely impaired by combined but not by separate removal of amygdala and hippocampus. Nature 273: 297-298, 1978.

184. Moore, R. Y. Catecholamine innervation of the basal forebrain: The septal area. J Comp Neurol 177: 665-684, 1978. 
185. Moore, R. Y. and F. E. Bloom. Central catecholamine neuron systems: anatomy and physiology of the dopamine systems. Annu Rev Neurosci 1: 129-169, 1978.

186. Morgan, D. N., J. H. McLean and R. M. Kostrzewa. Effects of 6-hydroxydopamine and 6-hydroxydopa on development of behavior. Pharmacol Biochem Behav 11: 309-312, 1979.

187. Morrison, J. H. and P. J. Magistretti. Monoamine and peptides in cerebral cortex. Trends Neurosci 6: 146-151, 1983.

188. Mueller, A. L., M. R. Palmer, B. J. Hoffer and T. V. Dunwiddie. Hippocampal noradrenergic responses in vivo and in vitro: characterization of alpha and beta components. Naunyn Schmiedebergs Arch Pharmacol 318: 259-266, 1982

189. Neill, D. B. and J. G. Herndon. Anatomical specificity within rat striatum for the dopaminergic modulation of DRL responding and activity. Brain Res 153: 529-538, 1978.

190. Nicoll, R. A., G. R. Siggins, N. Ling, F. E. Bloom and R. Guillemin. Neuronal actions of endorphins and enkephalins among brain regions: a comparative microiontophoretic study. Proc Natl Acad Sci USA 74: 2548-2588, 1978.

191. Norton, S. Amphetamine as a model for hyperactivity in the rat. Physiol Behav 11: 181-186, 1973.

192. Oades, R. D. Search and attention: Interactions of the Hippocampal-septal axis, adrenocortical and gonadal hormones. Neurosci Biobehav Rev 3: 327-338, 1979.

193. Oades, R. D. Types of memory or attention? Impairments after lesions of the hippocampus and limbic ventral tegmentum. Brain Res Bull 7: 221-226, 1981.

194. Oades, R. D. Dopaminergic agonistic and antagonistic drugs in the ventral tegmentum of rats inhibit and facilitate changes of food-search behaviour. Neurosci Lett 27: 75-80, 1981.

195. Oades, R. D. Impairments of search behaviour in rats after haloperidol treatment or hippocampal damage suggest a mesocorticolimbic role in cognition. Biol Psychol 12: 77-85, 1981.

196. Oades, R. D. Search strategies on a hole-board are impaired in rats with ventral tegmental damage: animal model for tests of thought disorder. Biol Psychiatry 17: 243-258, 1982.

197. Oades, R. D. Attention and Schizophrenia: Neurobiological Bases. London: Pitman Press, 1982.

198. Oades, R. D. Limbic, neocortical and midbrain interactions on measures of attention and memory in the holeboard search task. Behav Brain Res 8: 260-261, 1983.

199. Oades, R. D. The modulation of selective processes in learning by neocortical and limbic dopamine: studies of behavioural strategies. In: Brain Plasticity, Learning and Memory, edited by P. Schmitt and B. Will. New York: Plenum Press, to be published.

200. Oades, R. D. and R. L. Isaacson. The development of food search behavior by rats: effects of hippocampal damage and haloperidol treatment. Behav Biol 24: 327-338, 1978.

201. Oades, R. D., H. Simon and M. Le Moal. What does a rat do if it has an attentional deficit? Behav Brain Res 12: 215-216, 1984.

202. Oades, R. D., H. Simon and M. Le Moal. Modulation by dopaminergic neurons of neurobiological systems processing strategies in adaptive behaviour and learning. Behav Process 10: $180-181,1985$.

203. Oades, R. D., K. Taghzouti, H. Simon and M. Le Moal. Dopamine-sensitive alternation and collateral behaviour in a Y-maze: effects of d-amphetamine and haloperidol. Psychopharmacology (Berlin) 85: 123-128, 1985.

204. O'Donohue, T. L., W. R. Crawley and D. M. Jacobowitz. Biochemical mapping of the noradrenergic ventral bundle projection sites: evidence for a noradrenergic-dopaminergic interaction. Brain Res 172: 87-100, 1979.

205. Ögren, S. O. and K. Fuxe. Learning, brain noradrenaline and the pituitary adrenal axis. Med Biol 52: 399-405, 1974.

206. Ogren, S. O. and K. Fuxe. On the role of noradrenaline and the pituitary adrenal axis in avoidance learning: studies with corticosterone. Neurosci Lett 5: 291-296, 1977.

207. O'Shea, L., M. Saari, B. A. Pappas, R. Ings and K. Stange. Neonatal 6-hydroxydopamine attenuates the neural and behavioural effects of enriched rearing in the rat. Eur $J$ Pharmacol 92: 43-47, 1983.
208. Owen, F., T. J. Crow, M. Poulter, A. J. Cross, A. Longden and G. J. Riley. Increased dopamine receptor sensitivity in schizophrenia. Lancet 1: 223-226, 1978.

209. Owen, S., M. R. Boarder, J. A. Gray and M. Fillenz. Acquisition and extinction of continuously and partially reinforced running in rats with lesions of the dorsal noradrenergic bundle. Behav Brain Res 5: 11-41, 1982

210. Pappas, B. A. and S. K. Sobrian. Neonatal sympathectomy by 6-hydroxydopamine in the rat: no effects on behavior but changes in endogenous brain norepinephrine. Life $S_{c i}$ 11: 653$659,1972$.

211. Phillipson, O. T. Afferent projections to the ventral tegmental area of Tsai and interfasicular nucleus: a horseradish peroxidase study in the rat. J Comp Neurol 187: 117-144, 1979.

212. Phillipson, O. T. and A. C. Griffith. The neurons of origin of the mesohabenular dopamine pathway. Brain Res 197: 213$218,1980$.

213. Phillipson, O. T., P. C. Emson, A. S. Horn and T. Jessell. Evidence concerning the anatomical location of the dopamine-stimulated adenylate cyclase in the substantia nigra. Brain Res 136: 45-58, 1977.

214. Pisa, $M$. and $H$. C. Fibiger. Intact selective attention in rats with lesions of the dorsal noradrenergic bundle. Behas Neurosci 97: 519-533, 1983.

215. Pisa, M. and H. C. Fibiger. Evidence against a role of the rat's dorsal noradrenergic bundle in selective attention and place memory. Brain Res 272: 319-329, 1983.

216. Plaznik, A., W. Danysz and W. Kostowski. Some behavioral effects of microinjections of noradrenaline and serotonin into the hippocampus of the rat. Physiol Behav 31: 625-631. 1983.

217. Poirier, L. J., M. Giguère and R. Marchand. Comparative morphology of the substantia nigra and ventral tegmental area in the monkey, cat and rat. Brain Res Bull 11: 371-397, 1983.

218. Prado de Carvalho, L. and S. F. Zornestzer. The involvement of the locus coeruleus in memory. Behav Neural Biol 31: 173186,1981

219. Pycock, C. J., R. W. Kerwin and C. J. Carter. Effects of lesion of cortical dopamine terminals on subcortical dopamine receptors in rats. Nature 286: 74-77, 1980.

220. Quartermain, D. Catecholamine involvement in memory retrieval processes. In: Changing Concepts of the Nervous System, edited by A. R. Morrison and P. L. Strick. New York: Academic Press, 1982, pp. 667-681.

221. Raab, A. and G. Kojer. A 10 lesion and passive avoidance latency: Correlation with limbic tyrosine hydroxylase activity. Pharmacol Biochem Behav 17: 77-83, 1982.

222. Randt, C. T., M. E. Judge. K. A. Bonnet and D. Quartermain. Brain cyclic AMP and memory in mice. Pharmacol Biochem Behav 17: 667-680, 1982

223. Rebec, G. V. Auto- and post-synaptic dopamine receptors in the central nervous system. Monogr Neural Sci 10: 207-223, 1984.

224. Reynolds, G. P. Increased concentrations and lateral asymmetry of amygdala dopamine in schizophrenia. Nature 305: $527-529,1983$.

225. Rickert, E. J. and J. F. Lorden. Forebrain monoamines and associative learning: Il superconditioning/unblocking. Behav Brain Res 9: 201-211, 1983.

226. Ridley, R. M., H. F. Baker and T. A. J. Haystead. Perseverative behaviour after amphetamine: dissociation of response tendency from reward association. Psychopharmacology (Berlin) 75: 283-286, 1981.

227. Ridley, R. M., H. F. Baker, F. Owen, A. J. Cross and T. J Crow. Behavioural and biochemical effects of chronic am phetamine treatment in the vervet monkey. Psychopharmacology (Berlin) 78: 245-251, 1982.

228. Ritter, S. and L. Stein. Self-stimulation in the mesencephalic trajectory of the ventral noradrenergic bundle. Brain Res 82: $145-157,1974$.

229. Robbins, T. W. Cortical adrenaline, attention and arousal. Psychol Med 14: 13-23, 1984.

230. Robbins, T. W. and B. J. Everitt. Functional studies of the central catecholamines. Int Rev Neurobiol 23: 245-365, 1982. 
231. Robbins, T. W. and G. F. Koob. Selective disruption of displacement behaviour by lesions of the mesolimbic dopamine system. Nature 285: 409-411, 1980.

232. Robbins, T. W., B. J. Everitt, P. J. Fray, M. Gaskin, M. Carli and $\mathrm{C}$. de la Riva. The role of central catecholamines in attention and learning. In: Behavioral Models and the Analysis of Drug Action, edited by M. Y. Spiegelstein and A. Levy. Amsterdam: Elsevier Press, 1982, pp. 109-134.

233. Roberge, A. G., C. Boisvert and J. Everett. Monoamine roles in retention and reversal of delayed response in cats. Pharmacol Biochem Behav 12: 229-234, 1980.

234. Roberts, D. C. S., M. T. C. Price and H. C. Fibiger. The dorsal tegmental noradrenergic projection: an analysis of its role in maze learning. J Comp Physiol Psychol 90: 363-372, 1976.

235. Rogawski, M. A. and G. K. Aghajanian. Activation of lateral geniculate neurons by locus coeruleus or dorsal noradrenergic bundle stimulation: selective blockade by the alpha - $^{-}$ adrenoceptor antagonist prazosin. Brain Res 250: 31-39, 1982.

236. Saari, M. and B. A. Pappas. Behavioral effects of neonatal systemic 6-hydroxydopamine. Neuropharmacology 17: 863$871,1978$.

237. Saavedra, J. M. Changes in dopamine, noradrenaline and adrenaline in specific septal and preoptic nuclei after acute immobilization stress. Neuroendocrinology 35: 396-401, 1982.

238. Salafia, W. R. and A. M. Allan. Conditioning and latent inhibition with electrical stimulation of hippocampus. Physiol Psychol 8: 247-253, 1980.

239. Sara, S. J. Noradrenergic modulation of memory retrieval. In: Brain Plasticity, Learning and Memory, edited by P. Schmitt and B. Will. New York: Plenum Press, to be published.

240. Sara, S. J., B. Deweer and V. Leviel. Catecholamines and memory retrieval: attempts to find a role for noradrenaline in mediating reminder effects. Behav Brain Res 8: 274-275, 1983.

241. Scatton, B. Effect of dopamine agonists and neuroleptic agents on striatal acetyl choline transmission in the rat: evidence against dopamine receptor multiplicity. $J$ Pharmacol Exp Ther 220: 197-202, 1982.

242. Seeman, P. Brain dopamine receptors. Pharmacol Rev 32: $229-313,1980$

243. Segal, M. Norepinephrine modulates reactivity of hippocampal cells to chemical stimulation in vitro. Exp Neurol 77: 86-93, 1982.

244. Segal, M. Modulatory actions of noradrenaline on reactivity of central neurons to afferent stimulation. In: Brain Plasticity Learning and Memory, edited by P. Schmitt and B. Will. New York: Plenum Press, to be published.

245. Segal, M. and F. E. Bloom. Norepinephrine in the rat hippocampus: I. iontophoretic studies. Brain Res 72: 79-97, 1974.

246. Segal, M. and F. E. Bloom. The action of norepinephrine in the rat's hippocampus: III. Hippocampal cellular response to locus coeruleus stimulation in the awake rat. Brain Res 107: 499-511, 1976.

247. Segal, M. and F. E. Bloom. The action of norepinephrine in the rat's hippocampus: IV. The effects of locus coeruleus stimulation on evoked hippocampal unit activity. Brain Res 107: 513$525,1976$.

248. Segal, M. and A. Edelson. Effects of priming stimulation of catecholamine containing nuclei in rat brain in runway performance. Brain Res Bull 3: 203-206, 1978.

249. Segal, M., V. Pickel and F. Bloom. The projection of the nucleus locus coeruleus: an autoradiographic study. Life Sci 13: $817-821,1973$

250. Sessions, G. R., G. J. Kant and G. F. Koob. Locus coeruleus lesions and learning in the rat. Physiol Behav 17: 853-859, 1976.

251. Sharma, V. K., S. I. Harik, R. Busto and S. P. Banerjee. Effects of noradrenaline depletion on adrenergic and muscarinic receptors in the cerebral cortex, hippocampus and cerebellum. Exp Neurol 72: 179-194, 1981.

252. Shepard, P. D. and D. C. German. A sub-population of mesocortical dopamine neurons possesses autoreceptors. Eur $J$ Pharmacol 98: 455-456, 1984.
253. Shopsin, B., H. Klein, M. Aaronson and M. Collora. Clozapine, chlorpromazine and placebo in newly hospitalized acutely schizophrenic patients. Arch Gen Psychiatry 36: 657$664,1979$.

254. Simon, H. Neurones dopaminergiques A 10 et système frontal. J Physiol (Paris) 77: 81-95, 1981

255. Simon, H., M. Le Moal and A. Calas. Efferents and afferents of the ventral tegmental-A 10 region studied after local injection of ${ }^{3} \mathrm{H}$-leucine and horseradish peroxidase. Brain Res 178: $17-40,1979$

256. Simon, H., B. Scatton and M. Le Moal. Definitive disruption of spatial delayed alternation in rats after lesions in the ventral mesencephalic tegmentum. Neurosci Lett 15: 319-324, 1979.

257. Simon, H., B. Scatton and M. Le Moal. Dopaminergic A 10 neurones are involved in cognitive functions. Nature 288: $150-151,1980$.

258. Solomon, P. R. and D. M. Staton. Differential effects of microinjections of $d$-amphetamine into the nucleus accumbens or the caudate putamen on the rat's ability to ignore an irrelevant stimulus. Biol Psychiatry 17: 743-756, 1982.

259. Solomon, P. R., A. Crider, J. W. Winkelman, A. Turi, R. M. Kamer and L. J. Kaplan. Disrupted latent inhibition in the rat with chronic amphetamine or haloperidol-induced supersensitivity: relationship to schizophrenic attention disorder. Biol Psychiatry 16: 519-537, 1981.

260. Stein, L. Norepinephrine reward pathways: role in selfstimulation, memory consolidation and schizophrenia. In: 1974 Nebraska Symposium on Motivation, vol 24, edited by J. K. Cole and T. B. Sonderegger. Lincoln: University of Nebraska, 1975.

261. Stoof, J. C. and J. W. Kebabian. Independent in vitro regulation by the D2 dopamine receptor of dopamine-stimulated efflux of cyclic AMP and $\mathrm{K}^{+}$-stimulated release of acetyl choline from rat neostriatum. Brain Res 250: 263-270, 1982.

262. Storm, J. E., W. R. Millington and L. D. Fechter. Diethylthiocarbamate depresses the acoustic startle response in rats. Psychopharmacology (Berlin) 82: 68-72, 1984.

263. Sutherland, R. J., B. Kolb, I. Q. Whishaw and J. B. Becker. Cortical noradrenaline depletion eliminates sparing of spatial learning after neonatal frontal cortex damage in the rat. Neurosci Lett 32: 125-130. 1982.

264. Svensson, L. and S. Ahlenious. Suppression of exploratory locomotor activity by the local application of dopamine or 1-noradrenaline to the nucleus accumbens of the rat. Pharmacol Biochem Behav 19: 693-699, 1983.

265. Swanson, $L$. The projections of the ventral tegmental area and adjacent regions: Combined fluorescent retrograde tracer and immunofluorescence study in the rat. Brain Res Bull 9: 321$353,1982$.

266. Taghzouti, K. L'innervation dopaminergique du noyau accumbens et du septum: étude comportmentale. Thèse de 3 rd Cycle, Université de Bordeaux II, 1983.

267. Tassin, J. P., H. Simon, J. Glowinski and J. Bockaert. Modulations of the sensitivity of dopaminergic receptors in the prefrontal cortex and the nucleus accumbens: relationship to locomotor activity. In: Brain Peptides and Hormones, edited by E. Ricollu et al. New York: Raven Press, 1982, pp. 17-30.

268. Tassin, J. P., S. Lavielle, D. Herve, G. Blanc, A-M. Thierry, C. Alvarez, B. Berger and J. Glowinski. Collateral sprouting and reduced activity of the rat mesocortical dopaminergic neurons after selective destruction of the ascending noradrenergic bundles. Neuroscience 4: 1569-1582, 1979.

269. Tassin, J. P., L. Stinus, H. Simon, A-M. Thierry, M. Le Moal, B. Cardo and J. Glowinski. Relationship between the locomotor hyperactivity induced by $A 10$ lesions and the destruction of the fronto-cortical dopaminergic innervation in the rat. Brain Res 141: 267-281, 1978.

270. Thompson, R. Brain lesions impairing visual and spatial reversal learning in rats: components of the "general learning system" of the rodent brain. Physiol Psychol 10: 186-198, 1982.

271. Thompson, R. F., T. W. Berger, S. D. Berry, F. K. Hoehler, R. E. Kettner and D. J. Weisz. Hippocampal substrate of classical conditioning. Physiol Psychol 8: 262-279, 1980. 
272. Thornton, E. W. and J. C. Evans. The role of the habenula nuclei in the selection of behavioral strategies. Physiol Psychol 10: $361-367,1982$.

273. Thornton, E. W., A. J. Goudie and V. Bithell. The effects of neonatal 6-hydroxydopamine induced sympathectomy on response inhibition in extinction. Life Sci 17: 363-368, 1975.

274. Tremmel, F., M. D. Morris and G. F. Gebhart. The effect of forebrain norepinephrine depletion on two measures of response suppression. Brain Res 126: 185-188, 1977.

275. Trulson, M. E. and D. W. Preussler. Dopamine-containing ventral tegmental area neurons in freely moving cats: activity during the sleep-waking cycle and effects of stress. ExpN Neurol 83: $367-377,1984$.

276. Tulloch, I. F. and G. W. Arbuthnott. Electrophysiological evidence for an input from the anterior olfactory nucleus to the substantia nigra. Exp Neurol 66: 16-29, 1979.

277. Turner, B. H. Sensorimotor syndrome produced by lesions of the amygdala and lateral hypothalamus. J Comp Physiol Psychol 82: 37-47, 1973.

278. Ungerstedt, U. Striatal dopamine release after amphetamine or nerve degeneration revealed by rotational behaviour. Acta Physiol Scand Suppl 367: 49-68, 1971.

279. Ungerstedt, U. Adipsia and aphagia after 6-hydroxydopamine-induced degeneration of the nigro-striatal dopamine system. Acta Physiol Scand Suppl 367: 95-122, 1971.

280. U'Pritchard, D. C., T. D. Reisine, S. T. Mason, H. C. Fibiger and H. I. Yamamura. Modulation of rat brain alpha and beta adrenergic receptor populations by lesion of the dorsal noradrenergic bundle. Brain Res 187: 143-154, 1980.

281. Van den Bercken, J. H. L. and A. R. Cools. Evidence for a role of the caudate nucleus in the sequential organization of behaviour. Behav Brain Res 4: 319-337, 1982.

282. Van Kammen, D. P., J. P. Docherty, S. R. Marder, J. N. Rayner and W. E. Bunney. Long-term pimozide treatment differentially affects behavioral responses to dextroamphetamine in schizophrenia. Arch Gen Psychiatry 39: 275-281, 1982.

283. Van Loom, G. R. Brain catecholamines and ACTH secretion, studies on brain dopamine-beta-hydroxylase. In: Proc 6th Int Congr Pharmacol, Helsinki, vol 3, CNS and Behav Pharmacol, edited by M. Araakeinen. Oy Forssa: Forssan Kirjapaino, 1975, pp. 111-119.

284. Velley, L., B. Card and J. Bockaert. Modulation of rat brain $\alpha$-adrenoreceptor populations four weeks after stimulation of the nucleus locus coeruleus. Psychopharmacology (Berlin) 74: 226-231, 1981

285. Velley, L., B. Cardo and E. Kempf. Amélioration -es performances lors d'un apprentissage 4 semaines après stimulation du locus coeruleus: absence d'effet de la lésion du faisceau noradrénergique dorsal. $C R$ Seances Acad Sci 292: 943-946, 1981.

286. Velley, L., S. Nassif, E. Kempf and B. Cardo. Enhancement of learning four weeks after stimulation of the locus coeruleus in the rat: differential effects of dorsal noradrenergic bundle lesion and lesion of the locus coeruleus proper. Brain Res 265: 273-282, 1983
287. Verleye, M. and F. Bernet. Behavioral effects of lesions of the central noradrenergic bundles in the rat. Pharmacol Biochem Behav 19: 407-414, 1983 .

288. Vijayashankar, $N$. and $H$. Brody. A qualitative study of the pigmented neurons in the nuclei coeruleus and subcoeruleus in man as related to aging. $J$ Neuropathol Exp Neurol 38: 490497, 1979.

289. Wallace, M., G. Singer, J. Finlay and S. Gibson. The effect of 6-OHDA lesions of the nucleus accumbens septi on scheduleinduced drinking, wheel running and corticosterone levels in the rat. Pharmacol Biochem Behav 18: 129-136, 1983.

290. Watabe, K., K. Nakai and T. Kasamatsu. Visual afferents to norepinephrine containing neurons in cat locus coeruleus. Exp Brain Res 48: 66-80, 1982.

291. Watson, R. T., B. D. Miller and K. M. Heilman. Nonsensory neglect. Ann Neurol 3: 505-508, 1978.

292. Waterhouse, B. D. and D. J. Woodward. Interaction of norepinephrine with cerebrocortical activity evoked by stimulation of somatosensory afferent pathways. Exp Neurol 67: 11-34, 1980.

293. Weiner, I., R. E. Lubow and J. Feldon. Chronic amphetamine and latent inhibition. Behav Brain Res 2: 285-286, 1981

294. Wendlandt, S. and S. E. File. Behavioral effects of lesions of the locus coeruleus noradrenaline system combined with adrenalectomy. Behav Neural Biol 26: 189-201, 1979.

295. West, M. J. and A. H. Andersen. An allometric study of the area dentata in the rat and mouse. Brain Res Rev 2: 317-348, 1980.

296. Westerink, B. H. C. Determination of normetanephrine, 3,4dihydroxyphenylethyleneglycol (free and total), and 3methoxy-4-hydroxyphenylethyleneglycol (free and total) in rat brain by high performance liquid chromatography with electrochemical detection and effects of drugs on regional concentrations. I Neurochem 42: 934-942, 1984.

297. Wilson, W. J. Nucleus accumbens inhibits specific motor not non-specific classically conditioned responses. Brain Res Bull 10: 505-515, 1983.

298. Woodward, D. J. and B. D. Waterhouse. Interaction of norepinephrine with cerebrocortical activity evoked by stimulation of somatosensory afferent pathways in the rat. Soc Neurosci Abstr 4: 287, 1978.

299. Woodward, D. J., H. C. Moises, B. D. Waterhouse, B. J. Hoffer and R. Freedman. Modulatory actions of norepinephrine in the central nervous system. Fed Proc 38: 2109-2116, 1979.

300. Yamomoto, B. K. and C. R. Freed. Asymmetric dopamine and serotonin in nigrostriatal and limbic structures of the trained circling rat. Brain Res 297: 115-119, 1984.

301. Zis, A. P., H. C. Fibiger and A. G. Phillips. Reversal by L-DOPA of impaired learning due to destruction of the dopaminergic nigro-neostriatal projection. Science 185: 960 962,1974

302. Zornetzer, S. F., W. C. Abraham and R. Appleton. Locus coeruleus and labile memory. Pharmacol Biochem Behav 9: $227-234,1978$

\section{ADDENDUM}

Davis (1984) in a recent and comprehensive review supports the idea of a tonic role for NA activity in enhancing the startle response. This is largely based on the pharmacological evidence for a facilitation of startle with alpha $a_{1}$ agonists and an attenuation after the administration of alpha $\mathrm{a}_{2}$ agents or a slight depression after LC lesions. Possible evidence for a tuning mechanism is threefold, (a) differential habituation to tone and background noise after clonidine administration; (b) depending on impulse flow (spinalised/non-spinalised rats) clonidine increases or decreases the flexor reflex; (c) increases of NA transmission augment and decreases attenuate DA agonist mediated activation of the startle response. The absence of an effect of DA antagonists emphasizes the different mechanisms of action of the two CAs.

Davis, M. The mammalian startle response. In: Neural Mechanisms of Startle Behavior, edited by R. C. Eaton. New York: Plenum Press, 1984, pp. 287-351. 